\title{
Aerosolized Surfactants, Anti-Inflammatory Drugs, and Analgesics
}

\author{
Douglas F Willson MD
}

\author{
Aerosolized Surfactants \\ Aerosolized Anti-Inflammatory Agents \\ Inhaled Corticosteroids \\ Long-Acting Antimuscarinic Agents \\ Magnesium \\ Chromates \\ Lidocaine \\ Cyclosporin \\ Heparin \\ Miscellaneous Anti-Inflammatory Agents \\ Aerosolized Analgesics \\ Opioids \\ Local Anesthetics \\ Conclusions
}

\begin{abstract}
Drug delivery by aerosol may have several advantages over other modes, particularly if the lung is the target organ. Aerosol delivery may allow achievement of higher concentrations while minimizing systemic effects and offers convenience, rapid onset of action, and avoidance of the needles and sterile technique necessary with intravenous drug administration. Aerosol delivery may change the pharmacokinetics of many drugs, however, and an awareness of the caveats of aerosolized drug delivery is mandatory to ensure both safety and adequate drug delivery. This paper discusses the administration of surfactants, anti-inflammatory agents, and analgesics by the aerosol route. Key words: aerosolized surfactants; anti-inflammatory agents; analgesics; drug delivery. [Respir Care 2015;60(6):774-793. (C) 2015 Daedalus Enterprises]
\end{abstract}

\section{Introduction}

The inhalational route of drug administration may be ideal in diseases in which the lung is the primary target

Dr Willson is affiliated with the Division of Pediatric Critical Care, Department of Pediatrics, Children's Hospital of Richmond at Virginia Commonwealth University, Richmond, Virginia.

Dr Willson discloses a relationship with Discovery Laboratories.

Dr Willson presented a version of this paper at the 53rd RESPIRATORY CARE Journal Conference, "Aerosol Drug Delivery in Respiratory Care," held June 6-7, 2014, in St Petersburg, Florida.

Correspondence: Douglas F Willson MD, Division of Pediatric Critical Care, Children's Hospital of Richmond-VCU Medical Center, Old City organ or in which rapid onset of drug effect is required, and intravenous access is unavailable. Inhaled corticosteroids for inflammatory lung diseases such as asthma and COPD, for example, achieve local control with fewer of the adverse effects seen with systemic steroids. Similarly, in acute lung injury, aerosolization of surfactant rather than instillation avoids the transient airway obstruction and resultant hypoxia and hypotension that may be seen with instillation, and may allow more homogeneous drug distribution. Inhalation may also be an expedient approach

Hall, 1001 E Broad Street, 2nd Floor, Suite 205A, Richmond, VA 23219. E-mail: dwillson@mcvh-vcu.edu.

DOI: $10.4187 /$ respcare.03579 
for narcotics. Given the tremendous adsorptive area of the lung, the onset of action of inhaled narcotics may be nearly as immediate as intravenous drug administration and avoids the need for intravenous access.

Inhalational administration of a drug is not as straightforward as it may appear, however, and there are several important caveats to keep in mind. The potency of some drugs may change with aerosolization, and consequently, dose adjustment may be necessary. The drug delivery system may impact dose, as dilution with variable amounts of inspired gas may alter the percentage actually delivered into the lung. Particle size needs to be tailored to the specific lung target. ${ }^{1}$ Larger particles $(3-5 \mu \mathrm{m})$ tend to rain out in the upper or main bronchial airways ${ }^{2}$ and may be ideal for drugs such as bronchodilators, which primarily target smooth muscle, whereas smaller particles (1-3 $\mu \mathrm{m})$ allow deposition in the smaller airways and alveoli, which are targets for drugs such as aerosolized surfactants. ${ }^{3}$ Inhaled analgesics also require small-particle size specifically for the rapid onset of action that is possible with alveolar absorption. At the other extreme, particles smaller than $1 \mu \mathrm{m}$ may not deposit in the lung, remaining suspended in the gas stream with exhalation, and are consequently ineffective. Finally, wastage may be another major problem, particularly for expensive drugs, because the amount of drug nebulized may differ considerably from the amount of drug actually delivered.

Dosage, particle size, and specific drug target are each important considerations in deciding upon the aerosol route for delivery. This article addresses 3 specific drug classes for which the aerosol route may offer specific advantages.

\section{Aerosolized Surfactants}

Surfactant replacement may be beneficial in many types of pediatric and adult lung injury. Without surfactant, alveoli tend to collapse during normal tidal breathing, resulting in diminished lung compliance, ventilation/perfusion mismatching, and frequently respiratory failure. Exogenous surfactant administration has demonstrated efficacy in both the prevention and treatment of infantile respiratory distress syndrome (RDS), in which surfactant deficiency due to immaturity of the lung is primary. ${ }^{4}$ Surfactant dysfunction plays a comparable role in ARDS, although the dysfunction is not primarily deficiency but rather collateral damage in whatever process led to the initial lung injury (Fig. 1). ${ }^{5}$ The value of surfactant replacement in ARDS is, however, less clear and is the subject of ongoing clinical investigation.

Instillation is currently the only approved method for surfactant administration. Unfortunately, instillation requires placement of an artificial airway and at least transient positive-pressure ventilation, both of which may have adverse consequences in the unstable or fragile patient.
Intubation incurs the risk of sedation or anesthesia, the potential for endotracheal tube malposition, and possible direct injury to the airway. Positive pressure may result in injury related to the damaging effects of high pressure (barotrauma), lung overdistention (volutrauma), or repeated cycles of alveolar collapse and re-expansion (atelectrauma), collectively referred to as ventilator-induced lung injury. ${ }^{6}$ In preterm infants, ventilator-induced lung injury can occur quite rapidly, and the primary benefit of exogenous surfactant may actually be to reduce the exposure to positive-pressure ventilation. ${ }^{7}$ For example, mechanically ventilated animals have significantly higher levels of proinflammatory cytokines in the lung tissue compared with animals treated with CPAP alone. ${ }^{8}$ Instillation itself can also have adverse consequences. Instilling a large volume of liquid down an endotracheal tube results in transient airway obstruction that may precipitate hypoxia and hypercarbia, and the increase in intrathoracic pressure diminishes venous return to the heart and may result in hypotension and hemodynamic instability. These effects are generally transient but require careful monitoring and may preclude this therapy in unstable individuals. Despite these risks, multiple studies have demonstrated that surfactant administered by instillation is effective in both preventing and treating $\mathrm{RDS}^{4}$; the efficacy of surfactant in non-neonatal acute lung injury is less clear.

The first attempts to use exogenous surfactant in both RDS and ARDS were via aerosol and were unsuccessful. Robillard et $\mathrm{al}^{9}$ in 1964 and Chu et al ${ }^{10}$ in 1967 aerosolized dipalmitoylphosphatidylcholine, the primary surfactant phospholipid, to treat infants with RDS. Although clinical symptoms (retraction scores) improved, there was no impact on morbidity or mortality. A similar attempt to administer nebulized Exosurf, a synthetic surfactant devoid of surfactant apoproteins, to adults with ARDS was equally unsuccessful $30 \mathrm{y}$ later. ${ }^{11}$ There was no immediate improvement in oxygenation or any change in longer-term outcomes. Indeed, the early failures of aerosolized surfactant in preterm infants discouraged subsequent attempts to use exogenous surfactant as therapy. It was not until Enhörning et al ${ }^{12}$ in 1973 showed that instilled whole-lung surfactant was therapeutic in preterm rabbit pups that there was general agreement that RDS was secondary to surfactant deficiency. It was almost a decade (1981) before the successful use of surfactant was reported in human preterm neonates with RDS. ${ }^{13,14}$ Subsequent studies have demonstrated the value of instillation of exogenous surfactant in both the prevention and treatment of RDS, but there have been few attempts to deliver the drug by aerosol. A similar pattern has been observed with surfactant in nonneonatal lung injury. The early failure of aerosolized surfactant discouraged further experimentation, and the limited success of surfactant in non-neonatal lung injury to date has been solely with instillation. 


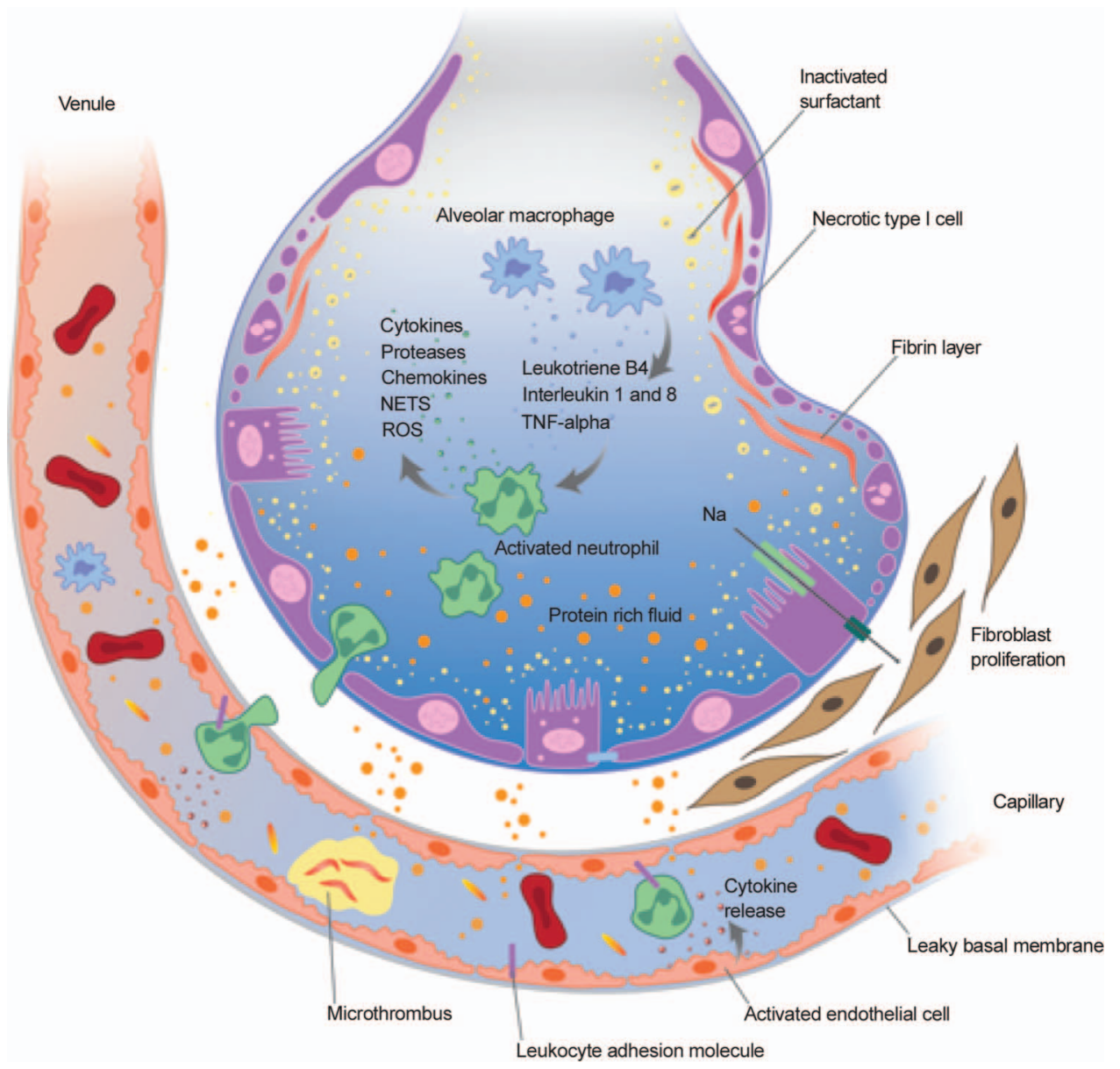

Fig. 1. Role of surfactant in non-neonatal acute lung injury. Increased pulmonary endothelial permeability, epithelial injury, and apoptosis lead to influx of protein-rich fluid that inactivates surfactant. Similarly, cytokines, neutrophils, reactive oxygen species (ROS), thrombin, and mechanical stretch contribute to an intense pulmonary inflammatory response, with accumulation of both pro-inflammatory and antiinflammatory mediators that may inactivate surfactant and decrease surfactant synthesis. Reduction in the production and turnover of surfactant leads to decreased lung compliance, resting lung volume, and functional residual capacity. NETS = neutrophil extracellular traps; TNF-alpha $=$ tumor necrosis factor alpha. Courtesy Dr Anil Sapru.

Aerosolization as a means of surfactant administration has several theoretical advantages over instillation. (1) Aerosolization avoids the aforementioned hypoxia and hypotension consequent to instilling a large volume of liquid down the endotracheal tube. (2) Aerosolization may produce more homogeneous surfactant distribution in the lung. ${ }^{15}$ (3) Less of the drug may be needed (as little as $2-3 \mathrm{mg} / \mathrm{kg}$ as opposed to the usual instilled dose of 100 $\mathrm{mg} / \mathrm{kg}$ ). ${ }^{16}$ (4) Aerosolization may allow surfactant to be administered without the need for an artificial airway. There are, however, limitations associated with surfactant aerosolization. As has been noted previously, the aerosol must be of the appropriate droplet or particle size. Particles larger than $5 \mu \mathrm{m}$ tend to rain out in the pharynx or proximal airways; droplets that are too small $(<1 \mu \mathrm{m})$ tend not to deposit in the alveolus and are exhaled. The Goldilocks size appears to be a mass median aerodynamic diameter of $\sim 1-2 \mu \mathrm{m}$. Fortunately, this can be achieved with a number of currently available nebulizers. Delivery of an adequate dose is also an issue. Although less surfactant may be needed if most reaches the alveoli, larger particle size $(>5 \mu \mathrm{m})$ may result in much of the aerosol raining out in the tubing, oropharynx, or proximal airways. The result may be that only a fraction of the aerosolized drug reaches the alveoli. Aerosol generators are also limited in the volume of liquid that can be aerosolized in a given time period. Dry power aerosols may offer an attractive alternative, although here also the optimal particle size, hydration status of the particles, and respiratory pattern may impact alveolar adsorption. Different aerosol devices and their advantages and disadvantages are described in Table 1 .

There have been few studies comparing aerosolized surfactant administration to instillation, and most of the studies are in animal models with sometimes contradictory results. The most comprehensive studies are those of Lewis 
Table 1. Advantages and Disadvantages of Aerosol Devices

\begin{tabular}{|c|c|c|}
\hline Device & Advantages & Disadvantages \\
\hline Breath-activated nebulizers & Delivers medication only during inhalation & Needs sufficient flow to trigger \\
\hline Monaghan AeroEclipse & Less medication wasted & $\begin{array}{l}\text { Takes longer to deliver medication } \\
\text { More expensive }\end{array}$ \\
\hline Breath-enhanced nebulizers & Targeted delivery & Very expensive \\
\hline $\begin{array}{l}\text { Adaptive aerosol delivery (Philips } \\
\text { Respironics I-neb) }\end{array}$ & Less wasted medication & Not ventilator-enabled \\
\hline Akita patient-individualized therapy & $\begin{array}{l}\text { Delivery adapts to patient's breathing } \\
\text { Can monitor patient adherence }\end{array}$ & Can be confused by incorrect use \\
\hline Vibrating-mesh nebulizers & Fast, quiet, portable & More expensive \\
\hline $\begin{array}{l}\text { Aerogen Aeroneb Go, Aeroneb Pro } \\
\text { Omron MicroAir } \\
\text { PARI eFlow } \\
\text { Odem TouchSpray }\end{array}$ & $\begin{array}{l}\text { Self-contained power source } \\
\text { Can optimize particle size for specific } \\
\text { drugs }\end{array}$ & $\begin{array}{l}\text { Not compatible with viscous liquids or those that } \\
\text { crystallize on drying } \\
\text { Cleaning can be difficult } \\
\text { Medication dose must be adjusted if transitioning } \\
\text { from a jet nebulizer }\end{array}$ \\
\hline Aerosol hood (child hood) & $\begin{array}{l}\text { Easy to apply } \\
\text { May be used for small infants in mild } \\
\text { respiratory distress }\end{array}$ & $\begin{array}{l}\text { Not well-validated } \\
\text { Facial deposition and environmental } \\
\text { contamination by aerosol } \\
\text { Unpredictable aerosol deposition }\end{array}$ \\
\hline $\begin{array}{l}\text { Metered-dose liquid inhalers } \\
\text { Respimat Soft Mist inhaler }\end{array}$ & $\begin{array}{l}\text { Easier to use than a pressurized MDI } \\
\text { Gives feedback } \\
\text { Very effective aerosol delivery }\end{array}$ & $\begin{array}{l}\text { More expensive } \\
\text { Small dosing chamber } \\
\text { Not suitable for use with a mechanical ventilator }\end{array}$ \\
\hline Engineered particles & $\begin{array}{l}\text { Can use a very simple and inexpensive } \\
\text { DPI }\end{array}$ & More difficult to manufacture particles \\
\hline $\begin{array}{l}\text { MannKind Technosphere } \\
\text { Novartis PulmoSphere }\end{array}$ & Breath-activated & $\begin{array}{l}\text { Not for use with all medications } \\
\text { May require more inhalations than with the usual } \\
\text { DPI }\end{array}$ \\
\hline High-flow nasal cannula delivery & $\begin{array}{l}\text { Able to deliver drug to patient in } \\
\text { respiratory distress } \\
\text { No need to stop } \mathrm{O}_{2} \text { to delivery medication }\end{array}$ & $\begin{array}{l}\text { No clinical data yet to support use or provide } \\
\text { dosing guidelines } \\
\text { May not be useful for some drugs } \\
\text { Higher upper-airway deposition }\end{array}$ \\
\hline $\begin{array}{l}\text { Data are from Reference } 17 . \\
\text { MDI }=\text { metered-dose inhaler } \\
\text { DPI = dry powder inhaler }\end{array}$ & & \\
\hline
\end{tabular}

et al. ${ }^{18,19}$ Their initial studies in premature lambs showed comparable improvement in ventilator efficiency indices, dynamic compliance, and pressure-volume curves with instilled whole-lung (Alveofact) and nebulized (both Alveofact and Survanta) surfactants. ${ }^{18}$ Nebulization resulted in greater deposition in the right upper lobe and trachea relative to the instilled drug, but the physiologic effects were comparable. However, later experiments in sheep with a lung lavage injury model demonstrated significant differences between surfactants and modes of administration. ${ }^{19}$ That study found that instilled whole-lung surfactant (bovine lung extract surfactant [BLES]) was the most effective in improving oxygenation and lung compliance (Fig. 2). Nebulized Survanta was next best and was significantly better than instilled Survanta. Interestingly, nebulized BLES had almost no effect. When analyzed in vitro, BLES appeared to be inactivated by nebulization as evidenced by the increased small-aggregate-to-large-aggregate ratio (small-aggregate surfactant is relatively devoid of surface activity, and large aggregate is considered the active surfactant). This reduction in large-aggregate surfactant after nebulization was not seen with Survanta, likely explaining why nebulized Survanta was effective and nebulized BLES was not.

Other animal studies of aerosolized surfactant have also had variable results depending on the aerosol device, how the aerosol was delivered into the lung, the lung injury model, and the specific surfactant used. A comparison of jet and ultrasonic nebulizer administration of Exosurf and Survanta in rabbits after lavage lung injury demonstrated significant differences in the amount of drug delivered determined by both the type of nebulizer (ultrasonic $>$ jet) and the specific surfactant (Exosurf $>$ Survanta). ${ }^{20}$ Irrespective of delivery method, however, neither drug had 

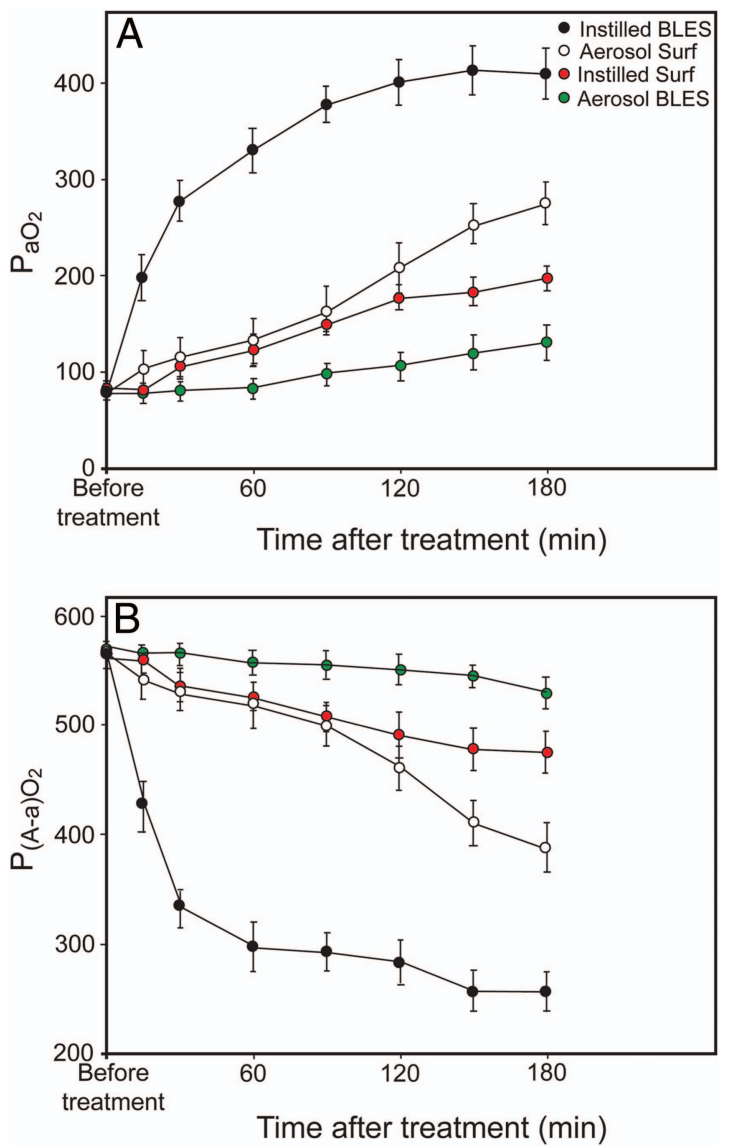

Fig. 2. $\mathrm{P}_{\mathrm{aO}_{2}}$ and alveolar-arterial oxygen difference $\left(\mathrm{P}_{(\mathrm{A}-\mathrm{a}) \mathrm{O}_{2}}\right)$ before treatment and during the $180 \mathrm{~min}$ after treatment. Values are means \pm SE. Animals treated with instilled bovine lung extract surfactant (BLES; $n=5$ ), aerosolized Survanta (Surf; $n=5$ ), and instilled Surf $(n=5)$ had significant improvements in both variables after treatment compared with their respective pretreatment values $(P<.01)$. Animals given aerosolized BLES $(n=5)$ had no significant changes in either variable over time. From Reference 19 , with permission.

significant effects on oxygenation. A new type of nebulizer called a capillary aerosol generator showed equivalent oxygenation improvement in a piglet lavage lung injury model when KL4 surfactant was delivered by instillation compared with aerosolization. ${ }^{21}$ Survival, lung histology, and interleukin-8 levels were all better with aerosolized and instilled KL4 surfactant relative to a control population supported by CPAP alone. Ruppert et $\mathrm{a}^{22}$ used a powder aerosolizer with Venticute, an artificial surfactant with recombinant surfactant protein $\mathrm{C}$, in both lung lavage and bleomycin rabbit injury models and showed rapid normalization of oxygenation to pre-injury levels. Additionally, aerosolized Venticute restored normal lung compliance in spontaneously breathing bleomycin-injured mice. Dijk et al ${ }^{23}$ compared nebulized and instilled Alveofact (a bovine whole-lung surfactant) in a rabbit lung lavage injury model. Both groups experienced improvement
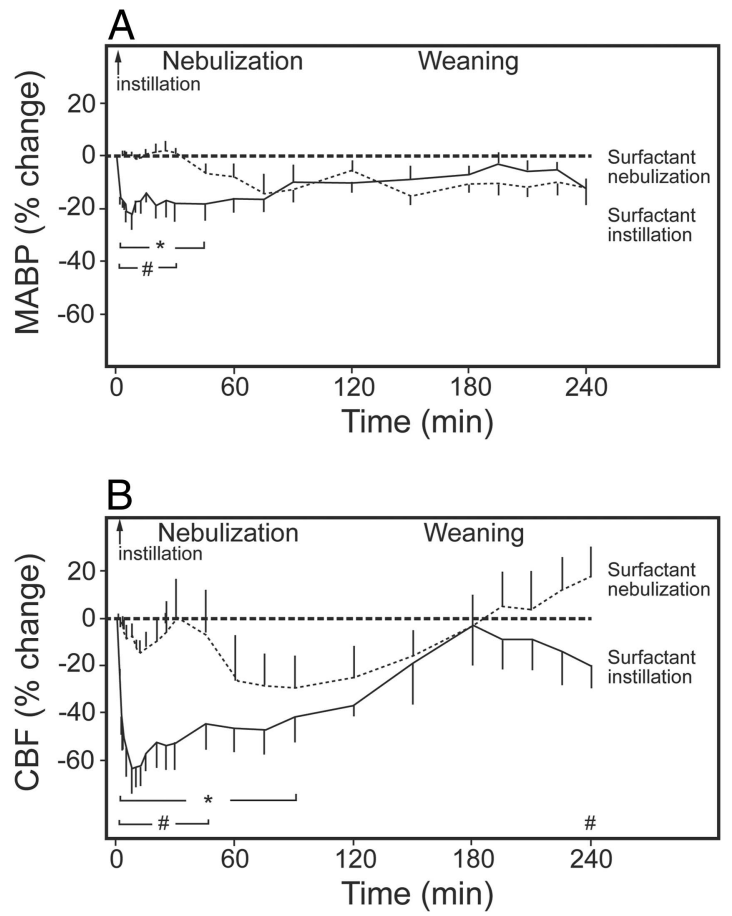

Fig. 3. Continuous measurements of mean arterial blood pressure (MABP) and cerebral blood flow (CBF) in the left carotid arteries of rabbits with severe respiratory failure treated by surfactant instillation or nebulization. All values are expressed as mean \pm SEM percentage change from pretreatment values $(n=6)$. ${ }^{*} P<.05$ vs pretreatment values; \# $P<.05$ between groups. From Reference 23, with permission.

in oxygenation, although the response to the instilled surfactant was nearly immediate, whereas the improvement with the nebulized surfactant occurred over a 2-h time period. Importantly, however, nebulization avoided the rapid change in mean blood pressure and cerebral blood flow related to changes in intrathoracic pressure associated with instillation (Fig. 3). An isolated perfused rabbit lung lavage injury model demonstrated diminished shunt fraction with both nebulized and instilled Alveofact, but blood flow to poorly ventilated areas was increased with instilled relative to nebulized surfactant. ${ }^{24}$ Aerosolized and instilled Curosurf in preterm lambs demonstrated comparable improvement in gas exchange and compliance, but cerebral hemodynamic changes during administration were less severe with the aerosol route. ${ }^{25}$ Wagner et al ${ }^{26}$ compared nebulized and instilled Curosurf $(200 \mathrm{mg} / \mathrm{kg})$ in a similar rabbit lung lavage injury model. Their nebulizer delivered a fog with a droplet size of $120 \pm 4 \mu \mathrm{m}$ via an intratracheal catheter. Both delivery methods resulted in rapid restitution of pre-injury oxygenation. Distribution of surfactant was somewhat better with the nebulized drug, although distribution was judged to be relatively homogeneous with both approaches. The investigators concluded that nebulization of surfactant into the trachea was effec- 
tive even when the droplet size was relatively large. They suggested that this approach might avoid the adverse effects of bolus instillation.

Experience with aerosolized surfactant in humans has been limited, and most has been in preterm neonates. An uncontrolled study of nebulized Alveofact in 20 preterm neonates (median gestational age of 31 weeks, birthweight of $1,680 \mathrm{~g}$ ) reported immediate improvements in oxygenation (alveolar-arterial difference), $\mathrm{P}_{\mathrm{aCO}_{2}}$, and dyspnea, although the improvement in breathing frequency did not reach statistical significance. ${ }^{27}$ The investigators used an Intersurgical RO252/ME jet nebulizer at a flow of $8 \mathrm{~L} / \mathrm{min}$ and delivered the aerosol directly via a nasopharyngeal tube. Fourteen of 20 infants did not require intubation, and the only adverse effect attributed to the nebulized surfactant was increased viscous secretions requiring frequent suctioning. A similar study administered Exosurf via nebulization to premature infants and reported no effect on oxygenation. ${ }^{28}$ Eight of 22 subjects required intubation and mechanical ventilation within $2 \mathrm{~h}$ of receiving nebulized Exosurf. Berggren et al ${ }^{29}$ compared CPAP with CPAP plus nebulized Curosurf in 24 premature infants and demonstrated no difference in immediate lung function or other outcomes. Finally, in an uncontrolled phase 2 study, 17 preterm infants were treated with nebulized Aerosurf (KL4 surfactant) delivered via a vibrating mesh nebulizer (Aeroneb Pro) while on CPAP. ${ }^{30}$ The investigators noted few adverse effects and improved oxygenation, although in the absence of a comparison group, their conclusions were limited. Five of 17 infants required intubation and subsequent instilled surfactant, but all survived. The investigators felt that drug delivery with the nebulizer was inconsistent, and this was a limitation of the study.

Experience with aerosolized surfactant in non-neonatal lung disease is more limited. The negative study of Exosurf in adults with ARDS has already been mentioned. ${ }^{11}$ The study compared nebulized Exosurf and nebulized halfnormal saline, the vehicle for Exosurf, in 725 adults with ARDS secondary to sepsis. There was no change in oxygenation or lung function and no improvement in mortality. The authors posited that the surfactant dose might have been insufficient because an estimated $95 \%$ of the nebulized drug was recovered from the ventilator tubing and that the nebulized half-normal saline in the control group may have actually been detrimental. It was also suggested that Exosurf is not a very effective surfactant because it is devoid of surfactant apoproteins. Surfactant proteins B and $\mathrm{C}$ appear to be vital for in vivo surface-tension reduction. ${ }^{31}$ In contrast, Anzueto et $\mathrm{al}^{32}$ reported improved sputum transport and overall pulmonary function with nebulized Exosurf compared with placebo in subjects with chronic bronchitis. Another study compared technetium-labeled aerosolized calfactant and saline in 8 subjects with cystic fibrosis and demonstrated similar distribution but with more rapid clearance of the technetium with the calfactant, suggesting that inhaled calfactant increased mucus clearance. ${ }^{33}$ In an interventional study in 5 young adults with cystic fibrosis, nebulized whole-lung surfactant (Alveofact) was administered daily for $5 \mathrm{~d}$ and failed to show any improvement in $\mathrm{FEV}_{1}$ or FVC. ${ }^{34}$ In contradistinction, a single case report of nebulized Exosurf in a patient with presumed reperfusion injury after lung transplant showed rapid improvement in compliance and oxygenation. ${ }^{35}$ Two small controlled studies in adults with asthma suggested that nebulized surfactant decreased airway responsiveness ${ }^{36}$ and improved pulmonary function ${ }^{37}$ during an asthma exacerbation, but an earlier study of nebulized surfactant in children with asthma was unsuccessful. ${ }^{38}$ Although surfactant administration could theoretically improve airway patency in the conducting airways ${ }^{39}$ in asthma, clinical data in humans are limited.

At present, the use of aerosolized surfactant is limited to experimental protocols. From animal studies, several conclusions appear warranted. (1) The droplet or particle size must be in the respirable range $(1-2 \mu \mathrm{m})$, although it is possible that the optimal range may vary for different surfactants and patients of different sizes (or ages). (2) The effective dose appears to be an order of magnitude lower when delivered by aerosol than by instillation. Unfortunately, this may still require a comparable amount of drug utilization, as the amount of drug actually delivered to the lung may bear little relationship to the amount of drug aerosolized. (3) As with instilled surfactant, it is likely that more complete surfactants (ie, those with surfactant apoproteins or apoprotein mimetics) will be more effective than surfactants without surfactant apoproteins. (4) Because much of the benefit of exogenous surfactant may lie in the avoidance of ventilator-induced lung injury, earlier administration is likely to be more effective than later. As such, effective aerosol delivery without the need for intubation or positive-pressure ventilation would be ideal. (5) Certain nebulizers may inactivate some surfactants (eg, BLES with ultrasonic nebulizer), so demonstration of surface activity after nebulization is imperative. (6) Surfactant distribution is important, as heterogeneous surfactant distribution may actually worsen ventilation/perfusion matching in the lung. Most animal studies suggest that distribution is more homogeneous with aerosolization compared with instillation, but most of the studies have been done with homogeneous lung injury models (lavage injury or prematurity). Clearly, more study is needed.

Aerosolization is a promising approach to surfactant administration, particularly because it may be possible to administer surfactant before intubation and institution of positive-pressure ventilation (Table 2). This may avoid the adverse effects associated with putting a large volume of liquid down the airway and the potential lung injury consequent to positive-pressure ventilation. What little data 
Table 2. Potential Advantages and Disadvantages of Surfactant Aerosolization

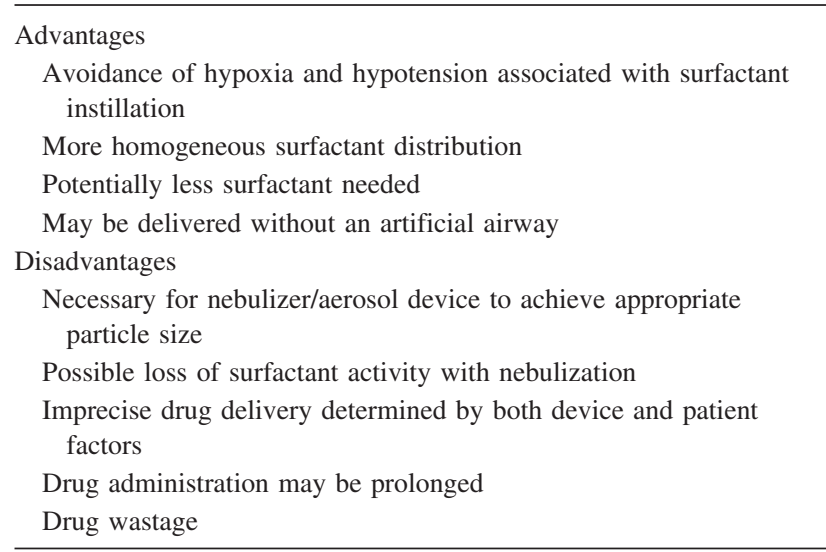

there are also suggest that surfactant distribution may be more homogeneous when the drug is aerosolized. Heterogeneous distribution is postulated to be one of the reasons for the failure of exogenous surfactant in the most recent randomized controlled trial (RCT). ${ }^{40}$ Clearly, however, aerosolized surfactant remains largely untested in human lung injury. As with any therapy, the devil may be in the details: specifically, the type of aerosol device, type of surfactant, dosage, timing, underlying lung injury, and likely other factors that we do not as yet understand. Surfactant aerosolization appears to have few adverse effects, so further phase 2 and 3 studies in humans are anticipated in the near future.

\section{Aerosolized Anti-Inflammatory Agents}

Many types of lung disease or lung injury are associated with inflammation. Although the inflammatory response is complex and rarely localized to just the lung, it makes intuitive sense that aerosolization would achieve the highest concentration of an anti-inflammatory agent into the lung while minimizing adverse effects on other organ systems. A large number of anti-inflammatory drugs are now available, although only a few have been formulated for inhalation. Inhaled (or suitable for aerosolization) antiinflammatory drugs and their utility in different diseases are described subsequently.

\section{Inhaled Corticosteroids}

Inhaled corticosteroids are perhaps the best example of the benefits of aerosolized compared with systemic antiinflammatory agents. Inhaled corticosteroids have eclipsed all other drugs for control of airway inflammation and are used in asthma, bronchopulmonary dysplasia, allergic bronchopulmonary aspergillosis, COPD, and several types of interstitial lung disease. Corticosteroids are potent antiinflammatory drugs with a multitude of effects. As outlined by de Benedictis and Bush, ${ }^{41}$ steroids inhibit inflammation through multiple mechanisms: (1) a direct genomic effect on nuclear gene expression by impacting transcription; (2) blocking nuclear factor kappa B, thereby decreasing transcription of cytokines, chemokines, cell adhesion molecules, and receptors for these molecules; (3) activating glucocorticoid receptors that have the downstream effect of inhibiting phospholipase $\mathrm{A}_{2}$ and cyclooxygenase-2, resulting in decreased prostaglandins, thromboxanes, and leukotrienes; (4) accelerating eosinophil apoptosis; and (5) enhancing the expression of $\beta_{2}$ receptors in the airway and reducing bronchial responsiveness to direct and indirect stimuli.

Systemically administered corticosteroids are associated with a large number of significant adverse effects; among the more serious are immune and adrenal suppression, hypertension, hyperglycemia, weight gain, growth suppression, gastrointestinal bleeding, and cataract formation. Unfortunately, systemic corticosteroids are also the most effective therapy for many types of inflammatory lung disease. In acute asthma, systemic steroids are the mainstay of therapy, and many would argue that bronchodilators only perform a holding action until the steroids have their effect. However, the adverse effects of systemic steroids preclude their continuous use in all but the most severe asthma patients. In chronic lung disease of prematurity (bronchopulmonary dysplasia), systemic steroids allow more rapid weaning from mechanical ventilation and earlier extubation but have been associated with significant decrements in development years later. ${ }^{42,43}$ Consequently, they are not used routinely in preterm infants. In cystic fibrosis, systemic steroids have been shown to slow the deterioration in lung function but at the cost of growth impairment. ${ }^{44}$ Similarly, short-term systemic steroids may be helpful in COPD but have been associated with increased rates of complications, including muscle atrophy and pneumonia. ${ }^{45,46}$

Inhaled corticosteroids achieve many of the benefits of systemic steroids while moderating their adverse effects. For the long-term control of asthma, inhaled corticosteroids are the most potent and consistently effective medications for achieving overall treatment goals. ${ }^{4-49}$ Relative to placebo, inhaled corticosteroids reduce asthma symptoms and reduce the frequency and severity of exacerbations. ${ }^{48}$ Low-dose inhaled corticosteroids are considered safe, with the most common adverse effects limited to oral candidiasis and dysphonia, both of which can be minimized by oral rinsing after administration. In children, however, a prospective RCT showed mild growth retardation with inhaled corticosteroids compared with placebo. ${ }^{50}$

Daily administration of inhaled corticosteroids is the generally applied approach, but a study in adults suggested 
Table 3. Lung Deposition and Particle Size Comparison of Steroid Inhalers

\begin{tabular}{lcc}
\hline \hline \multicolumn{1}{c}{ Inhaled Steroid } & MMAD (mm) & Lung deposition (\%) \\
\hline Fluticasone powder inhaler & 4.0 & 15 \\
Triamcinolone & 4.5 & 14 \\
CFC flunisolide & 3.8 & 19 \\
CFC beclomethasone & 3.5 & 8 \\
CFC fluticasone & 2.6 & 13 \\
HFA flunisolide solution & 1.2 & 68 \\
HFA beclomethasone solution & 1.1 & 56 \\
HFA ciclesonide solution & 1.0 & \\
& & \\
MMAD = mass median aerodynamic diameter & & \\
CFC $=$ chlorofluorocarbon & & \\
HFA $=$ hydrofluoroalkane & & \\
\end{tabular}

that intermittent short courses of inhaled corticosteroids at the onset of an asthma exacerbation might be as effective as continuous daily use. ${ }^{51} \mathrm{~A}$ meta-analysis of 4 pediatric and 2 adult studies demonstrated, however, that daily compared with intermittent use resulted in better asthma control and less need for rescue administration of $\beta_{2}$ agonists. ${ }^{52}$ A Cochrane review of 55 studies suggested that inhaled corticosteroids did not consistently reduce the rate of decline in $\mathrm{FEV}_{1}$ in subjects with COPD but did reduce the number of exacerbations and improved quality of life. ${ }^{53}$ Inhaled corticosteroids have not been found helpful in chronic lung disease of prematurity. ${ }^{54}$

A large number of inhaled corticosteroid preparations are available (Table 3). Since the Montreal Protocol in 1987, chlorofluorocarbons have been replaced by hydrofluoroalkanes as propellants in inhaled corticosteroid metered-dose inhalers. The reformulations allowed new product development and the development of inhaled corticosteroids with smaller particle size. Although steroid receptors are present throughout the respiratory tract, 55 particle size does seem to matter. In asthma RCTs of socalled ultrafine hydrofluoroalkanes, beclomethasone showed equal efficacy at half the dose of the larger particle chlorofluorocarbon beclomethasone (Fig. 4). 57,58 Similar findings were demonstrated with flunisolide. ${ }^{59}$ Compared with large-particle inhaled corticosteroids, small-particle inhaled corticosteroids result in a redistribution of dose to the airways, with less deposition in the oropharynx and more deposition in the lung and periphery of the lung. This may be particularly critical in children, in whom the differences in airway anatomy and level of coordination and cooperation greatly favor smaller particle size. ${ }^{60}$ Smaller particle size increases residence time in the aerosol and allows greater lung penetration and increased drug deposition to the lower respiratory tract. An additional benefit may be a lower incidence of oral candidiasis and dysphonia, frequent adverse effects of inhaled corticosteroids,

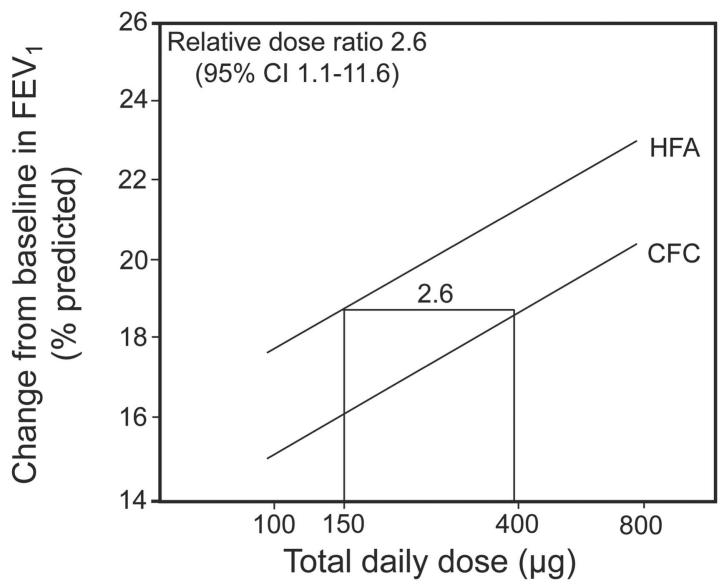

Fig. 4. Dose-comparison calculation shows that it would take 2.6 times the dose of a large-particle inhaled steroid (chlorofluorocarbon [CFC] beclomethasone dipropionate) to achieve the same improvement in $\mathrm{FEV}_{1}$ compared with an ultrafine-particle inhaled steroid (hydrofluoroalkane [HFA] beclomethasone propellant). From Reference 56, with permission.

because the ultrafine-particle size results in less upperairway deposition of the drug. 57-60

Concern about possible side effects of higher doses of inhaled corticosteroids for asthma treatment has prompted the development of formulations that combine inhaled corticosteroids with long-acting $\beta_{2}$ agonists. These have been shown to decrease the required dose of inhaled corticosteroids while improving asthma control in some studies. ${ }^{61}$ National guidelines suggest, however, that long-acting $\beta_{2}$ agonists be added only when control cannot be achieved with monotherapy (Table 4). ${ }^{62}$ They do carry the FDA black box warning that they may increase the risk of sudden death thought to be related to down-regulation of $\beta_{2}$ receptors, although this has not been reported when combined with inhaled corticosteroids. The combined products are substantially more expensive than inhaled corticosteroids alone, although overall cost of any medication must take into account the effectiveness and cost of drug failure; one emergency department visit or one hospital admission can cost as much as an entire year's supply of the inhaled corticosteroid/long-acting $\beta_{2}$-agonist combination drugs.

As a final note on inhaled corticosteroids, no drug is effective if ineffectively administered! Children, particularly small children, present significant challenges for aerosolized drug delivery. Mask administration is the norm because cooperation is often less than optimal. Unfortunately, the infant nose is an effective aerodynamic filter, and infants and young children tend to be nose breathers. Infants and children are also generally not cooperative with breath-holding, which tends to allow an aerosol to settle in the distal lung, and crying greatly reduces lung deposition. One of the advantages of the ultrafine inhaled corticosteroid preparations is that they may require less 
Table 4. Asthma Therapy

\begin{tabular}{|c|c|c|c|c|}
\hline \multicolumn{5}{|c|}{ Treatment Steps } \\
\hline Step 1 & Step 2 & Step 3 & Step 4 & Step 5 \\
\hline \multirow[t]{5}{*}{$\begin{array}{l}\text { Controller } \\
\text { options* }\end{array}$} & Select one & $\begin{array}{l}\text { As needed, fast-acting } \beta_{2} \text { agonist } \\
\text { Select one }\end{array}$ & $\begin{array}{l}\text { To Step } 3 \text { treatment, add one } \\
\text { or more }\end{array}$ & $\begin{array}{l}\text { To Step } 4 \text { treatment, } \\
\text { add either }\end{array}$ \\
\hline & $\begin{array}{l}\text { Low-dose inhaled } \\
\text { corticosteroids }\end{array}$ & $\begin{array}{l}\text { Low-dose inhaled corticosteroids plus } \\
\text { long-acting } \beta_{2} \text { agonist }\end{array}$ & $\begin{array}{l}\text { Medium- or high-dose inhaled } \\
\text { corticosteroids plus long- } \\
\text { acting } \beta_{2} \text { agonist }\end{array}$ & $\begin{array}{l}\text { Oral glucocorticosteroid } \\
\text { (lowest dose) }\end{array}$ \\
\hline & Leukotriene modifier $\dagger$ & $\begin{array}{l}\text { Medium- or high-dose inhaled } \\
\text { corticosteroids }\end{array}$ & Leukotriene modifier & Anti-IgE treatment \\
\hline & & $\begin{array}{l}\text { Low-dose inhaled corticosteroids plus } \\
\text { sustained-release theophylline }\end{array}$ & Sustained-release theophylline & \\
\hline & & $\begin{array}{l}\text { Low-dose inhaled corticosteroids plus } \\
\text { sustained-release theophylline }\end{array}$ & & \\
\hline \multicolumn{5}{|c|}{$\begin{array}{l}\text { Adapted from Reference } 62 \text {. Alternative treatments include inhaled anticholinergics, short-acting oral } \beta_{2} \text { agonists, and short-acting theophylline. Regular dosing with short-acting and long-acting } \beta_{2} \\
\text { agonists is not advised unless accompanied by regular use of inhaled corticosteroids. } \\
\text { * Recommended treatment based on group mean data. } \\
\dagger \text { Receptor antagonist or synthesis inhibitors. } \\
\text { IgE }=\text { immunoglobulin E }\end{array}$} \\
\hline
\end{tabular}

coordination to administer. Multiple studies in children demonstrate that smaller is better and might actually result in fewer side effects, as lower doses of inhaled corticosteroids may be sufficient. ${ }^{60}$

\section{Long-Acting Antimuscarinic Agents}

Cholinergic parasympathetic nerves contribute to the elevated smooth muscle tone in COPD and asthma, and antimuscarinic agents are primarily bronchodilators. However, acetylcholine can be also released from non-neuronal cells to act on airway smooth muscle and other cells involved in the inflammatory response, ${ }^{63}$ and the antimuscarinic agents may consequently decrease inflammation. These agents have become a mainstay of therapy in COPD, and their use is gaining increasing acceptance in asthma treatment. How much of the improvement possibly relates to anti-inflammatory versus bronchodilator effect is unclear. There is extensive evidence that long-acting antimuscarinic agents improve symptom control and quality of life in subjects with COPD, ${ }^{64}$ and their efficacy in asthma is also being studied. ${ }^{65} \mathrm{~A}$ study comparing tiotropium to salmeterol (a long-acting $\beta_{2}$ agonist) and inhaled corticosteroids in chronic poorly controlled asthma demonstrated equal efficacy; both were superior to doubling the dose of inhaled corticosteroids (Fig. 5). ${ }^{64}$ As with inhaled corticosteroids and long-acting $\beta_{2}$ agonists, inhalation of these agents allows more effective drug delivery with fewer side effects relative to systemic administration.

Four long-acting antimuscarinic agents are commercially available in the United States, although several others are undergoing phase 3 trials. Tiotropium bromide, marketed as Spiriva, has specificity for the M3 muscarinic receptor, making it less likely to produce tachycardia. Aclidinium (Almirall) has similar selectivity and duration but has faster onset in clinical trials. ${ }^{66}$ Both have an approximate 24-h duration of effect. Ipratropium (Atrovent) is a short-acting antimuscarinic agent, and its use is limited to exacerbations of asthma and possibly COPD. Interestingly, the method of delivery of these agents may result in significant differences in outcomes. The aqueous solution of tiotropium delivered via an inhaler (Respimat) has been associated with increased mortality relative to placebo in several COPD studies, as well as relative to reported rates in studies using a powder inhaler (HandiHaler). ${ }^{67}$ However, a subsequent large RCT failed to show a mortality difference, and at present, both formulations are available for clinical use in the United States. ${ }^{68}$

The use of long-acting antimuscarinic agents in COPD is established, and as with successive generations of $\beta_{2}$ agonists, it is likely that more receptor-selective agents (specifically the M3 muscarinic receptor) will be developed. Their use in asthma is also likely to increase given their demonstrated superiority over higher inhaled corticosteroid doses in adult asthma. ${ }^{67}$ Long-acting $\beta_{2}$ agonist/long-acting antimuscarinic agent combination drugs may have synergistic effects and are currently being tested in COPD. ${ }^{69} \beta_{2}$ agonists can amplify the bronchial smooth muscle relaxation directly induced by the muscarinic antagonist by decreasing the release of acetylcholine via modulation of cholinergic neurotransmission. In turn, muscarinic antagonists may reduce the bronchoconstrictor effects of acetylcholine. Whether these combination agents will find a place in the treatment of chronic asthma re- 

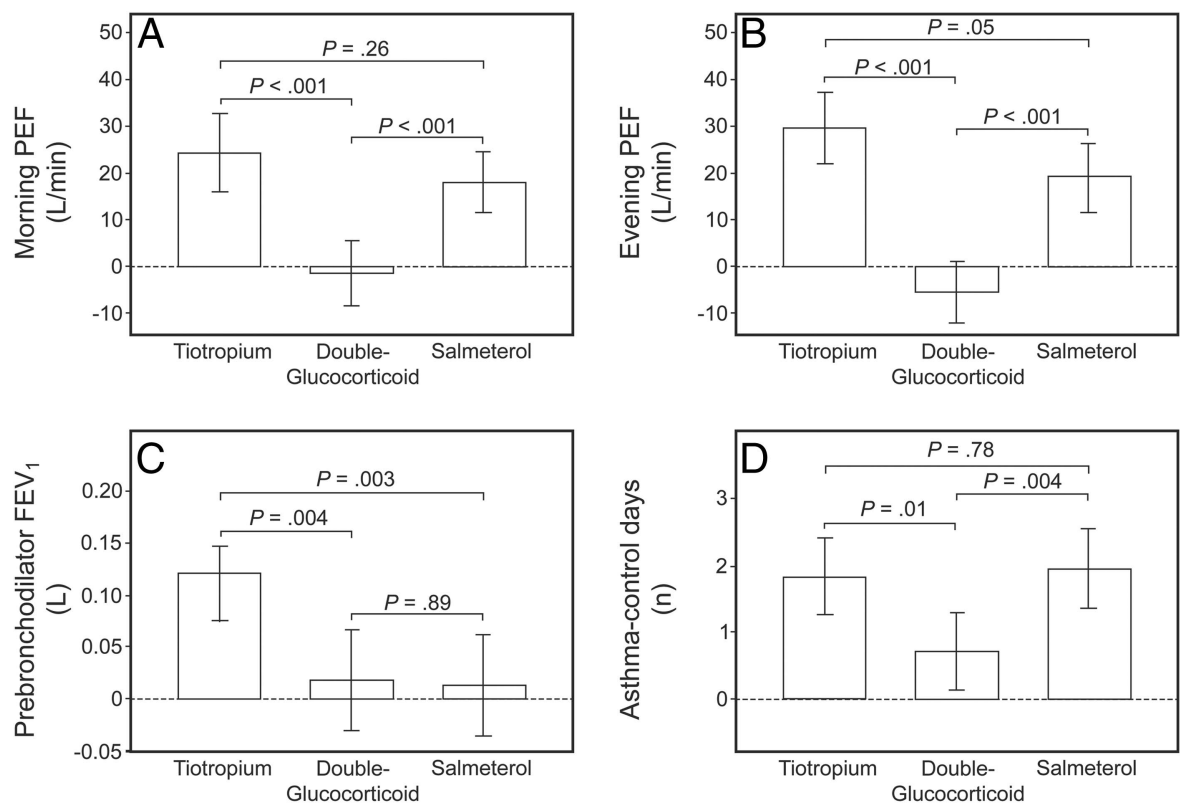

Fig. 5. Mean differences among subjects receiving tiotropium, those receiving double glucocorticoid, and those receiving salmeterol with respect to the morning peak expiratory flow (PEF) (A), evening PEF (B), pre-bronchodilator $\mathrm{FEV}_{1}(\mathrm{C})$, and proportion of asthma-control days per 14-d period (D). Whiskers indicate 95\% Cl. From Reference 64, with permission.

mains to be seen. As stated previously, their anti-inflammatory effects are debatable, and consequently, their potential use in other inflammatory lung diseases is unclear.

\section{Magnesium}

Magnesium is not a classic anti-inflammatory agent but has an antioxidant effect on neutrophils in addition to attenuating bronchoconstriction through direct smooth muscle relaxation. ${ }^{70}$ Studies with intravenous magnesium have generally not shown benefit in adult asthma ${ }^{71,72}$ but have shown a minimal but significant effect on lung function (generally $\mathrm{FEV}_{1}$ or peak expiratory flow) in pediatric asthma. ${ }^{73,74}$ In the multi-center pediatric MAGNETIC study, inhaled magnesium compared with saline (added to albuterol and ipratropium) resulted in a statistically significant improvement in asthma severity score at $60 \mathrm{~min}$. This did not, however, result in a difference in any longerterm outcome (stay, intubation, or pediatric ICU admission)..$^{73}$ The investigators noted that the improvement was most significant in the severe asthma subjects and those in whom symptoms had been relatively acute. Inhaled magnesium had no reported adverse effects. A comparable study in adults, the $3 \mathrm{Mg}$ trial, which compared intravenous or inhaled magnesium to placebo, suggested no effect of inhaled magnesium and a minimal but significant effect of intravenous magnesium. ${ }^{72}$ For both inhaled and intravenous magnesium, children with asthma appear to benefit more than adults with asthma.
Magnesium has the significant advantage that it is cheap and relatively devoid of adverse effects other than a warm feeling due to vasodilation when given as an intravenous bolus. There is, however, little evidence of prolonged bronchodilation or any improvement in ultimate outcomes in acute asthma. Given the suggestion that it may be effective in more severe asthmatic cases, ${ }^{74}$ inhaled or intravenous magnesium is frequently added when the standard nebulized $\beta_{2}$ agonists plus ipratropium do not completely resolve clinical symptoms.

\section{Chromates}

Sodium cromoglycate (cromolyn) and nedocromil are anti-inflammatory drugs delivered solely by the inhalational route. These drugs acutely inhibit mast cell degranulation in the airway. Longer-term treatment has also been shown to decrease the number of eosinophils, mast cells, and lymphocytes and to reduce the expression of intracellular adhesion molecule-1 and endothelial-leukocyte adhesion molecule-1 in bronchial biopsy after 12 weeks. ${ }^{75}$ Several decades ago, chromates were the first-line agents for mild-to-moderate asthma and exercise-induced bronchospasm, but their use has been eclipsed by inhaled corticosteroids. The drugs were problematic in requiring administration 3-4 times/d but had the major advantage of being essentially devoid of side effects other than rare anaphylaxis or allergic reactions. A meta-analysis (Cochrane review) of 1,026 subjects in 23 trials performed 
between 1970 and 1997 showed that cromolyn was no better than placebo when comparing symptom-free days, although bronchodilator use was less in subjects taking cromolyn. ${ }^{76}$ Cromolyn then became relegated to the second tier for asthma, at least in children, and its use has almost disappeared.

An interesting review by Keller and Schierholz ${ }^{77}$ suggests that the chromates have not been given an adequate trial. They argue that previous studies of cromolyn and its sister drug, nedocromil, were inadequate because drug delivery via a metered-dose or dry powder inhaler resulted in particles of $>5 \mu \mathrm{m}$, which are not in the respirable range. Because of the extreme hydroscopic nature of the drug, particle size tended to increase rapidly over the life of the metered-dose inhaler or dry powder inhaler due to water ingression into the canister, rendering delivered particle size ineffective. The authors suggest that newer nebulizers (eg, PARI LC Sprint and eFlow 30S) deliver particles in the respirable range $(3-3.5 \mu \mathrm{m})$, resulting in more effective and consistent drug delivery without the problem of inconsistency in particle size or dose. The authors argue that the necessity for 3-4 times daily administration may have been more reflective of the inconsistencies in dose delivery than actual drug half-life. Despite the purported inadequacies of early studies and the development of more effective nebulizers, cromolyn remains relegated to second-tier status in both the European and United States asthma guidelines.

\section{Lidocaine}

Similar to corticosteroids, lidocaine shortens eosinophil survival and inhibits cough in response to a variety of stimuli. ${ }^{78,79}$ Several uncontrolled studies suggest efficacy in mild-to-moderate asthma. A controlled blinded study by Hunt et $\mathrm{al}^{80}$ in 50 adults with asthma administered $100 \mathrm{mg}$ of lidocaine by aerosol versus saline 4 times/d showed improved $\mathrm{FEV}_{1}$, less nighttime awakening, decreased bronchodilator usage, and decreased blood eosinophil counts. However, a subsequent study ${ }^{81}$ failed to show improvement relative to a placebo control, although the dose was considerably smaller (40 mg twice/d) relative to the Hunt study $^{80}$ (100 mg 4 times/d). Although ostensibly both studies were blinded, the numbness associated with lidocaine inhalation rendered blinding somewhat questionable. Lidocaine has demonstrated efficacy in intractable cough but has not been shown to be effective in the treatment of acute asthma. Indeed, a significant percentage of subjects in the Hunt study ${ }^{80}$ had a measurable immediate decrement in $\mathrm{FEV}_{1}$ associated with inhaled lidocaine. At present, it appears unlikely that inhaled lidocaine will find a place as an anti-inflammatory agent in the treatment of asthma or other pulmonary inflammatory diseases.

\section{Cyclosporin}

Cyclosporin is a calcineurin inhibitor commonly used to prevent or treat rejection in a variety of solid organ transplants by blocking T lymphocyte activation. Systemic drug administration requires careful monitoring because of a low therapeutic index, particularly renal toxicity. Aerosolization has particular appeal in lung transplantation because the lung is the target, and it may be possible to achieve a higher lung concentration while minimizing toxicity. Lung transplant has the highest mortality of all solid organ transplants, with both acute and chronic rejection the main causes of graft failure and death. Animal studies of lung transplantation demonstrate that inhaled cyclosporine can achieve high graft concentrations with minimal toxicity, ${ }^{82,83}$ and these findings have been supported by open label trials in human transplant subjects. ${ }^{84,85}$ An RCT of inhaled cyclosporine versus placebo in 58 subjects after lung transplantation demonstrated that whereas there was no improvement in rates of acute rejection, survival and chronic rejection-free survival were significantly greater with inhaled cyclosporine relative to placebo. ${ }^{86}$ Nebulized cyclosporine has also been evaluated for safety and pharmacokinetics in healthy controls and asthma subjects. ${ }^{87}$ Serum levels were much lower than with comparable oral doses, and repeated inhaled doses were well tolerated without any apparent systemic immune suppression. Aerosolized potent immunosuppressive agents such as cyclosporine and tacrolimus are likely to be used increasingly in the future but remain largely experimental at present.

\section{Heparin}

Aerosolized heparin has demonstrated ability to prevent exercise-induced bronchoconstriction ${ }^{88,89}$ and has been used to treat plastic bronchitis, ${ }^{90}$ but it appears to have particular efficacy in acute lung injury due to smoke inhalation. It is not clear if the primary effect is as an antiinflammatory agent or simply as a locally active anticoagulant. Smoke inhalation injury is due primarily to chemical toxins in smoke as opposed to thermal injury. The initial injury is limited to the trachea and main bronchial airways, with exfoliation of the airway mucosa, increased microvascular permeability, increased mucus secretion, and a profound inflammatory response. Fibrinocellular pseudomembranes form within hours of injury, and it is postulated that early inhaled heparin may decrease fibrin formation and avoid the resultant airway obstruction. ${ }^{91}$ Several retrospective clinical studies in humans have shown variable improvement in mortality ${ }^{92,93}$ and lung injury ${ }^{92-94}$ scores relative to historical controls. Importantly, none of the studies identified any increase in bleeding complications. The study was NCT01454869 but was withdrawn. 


\section{Miscellaneous Anti-Inflammatory Agents}

A number of other agents have been trialed as aerosol anti-inflammatory therapy for asthma and other lung diseases. These include dapsone, ${ }^{95}$ furosemide, ${ }^{96}$ ketoprofen, ${ }^{97}$ antihistamines (azelastine), ${ }^{98}$ interferon, ${ }^{99}$ and pentoxifylline, ${ }^{100}$ but they are either still experimental or have proven ineffective. As stated previously, aerosol delivery of antiinflammatory agents is particularly attractive because of the potential to maximize drug levels and presumably therapeutic effect while minimizing side effects. It is likely that aerosol preparations of many anti-inflammatory agents will be trialed in the future.

\section{Aerosolized Analgesics}

\section{Opioids}

As evidenced by the tragic deaths in the Russian military's attempt to incapacitate Chechen rebels in a Moscow theater, ${ }^{101}$ opioid analgesics can be delivered quite effectively by aerosol. This may be a particularly attractive route outside the hospital setting, where intravenous access may be problematic in terms of both availability and the necessary skill set to administer intravenous drugs sterilely and safely. Relative to oral agents, inhaled opioids offer more rapid onset for breakthrough pain and may also avoid the difficulties with oral medications that patients undergoing chemotherapy experience due to nausea or vomiting.

Narcotics can be effectively administered via aerosol, but the pharmacokinetics and pharmacodynamics are influenced by a number of factors. The bioavailability or actual dose delivered may vary depending on the aerosol device and whether it is continuous or breath-activated. Larger particles may condense in the nose, oropharynx, and equipment, making determination of delivered dose difficult. Continuous aerosol devices compared with breathactivated devices may result in much of the dose being lost to the environment. Indeed, many of the studies comparing inhaled and intravenous narcotic administration are confounded by these effects. ${ }^{102-107}$ Newer breath-activated devices, such as the AERx PMS system (Fig. 6), ${ }^{102,103}$ are more reliable, with estimates approaching $60-75 \%$ bioavailability relative to intravenous dosing. Staccato fentanyl for handheld inhalers produces a single metered dose of highly purified fentanyl that produces peak serum levels and area under the curve concentrations very comparable to those produced by intravenous fentanyl. ${ }^{104}$ Droplet size may also impact drug metabolism and delivery. Krajnik et al ${ }^{103}$ compared 2 different nebulizers, delivering droplet sizes of $0.5-2$ and $2-5 \mu \mathrm{m}$, respectively, and demonstrated significant differences in proportion of morphine-3-glucuronide to morphine-6-glucuronide. They surmised that

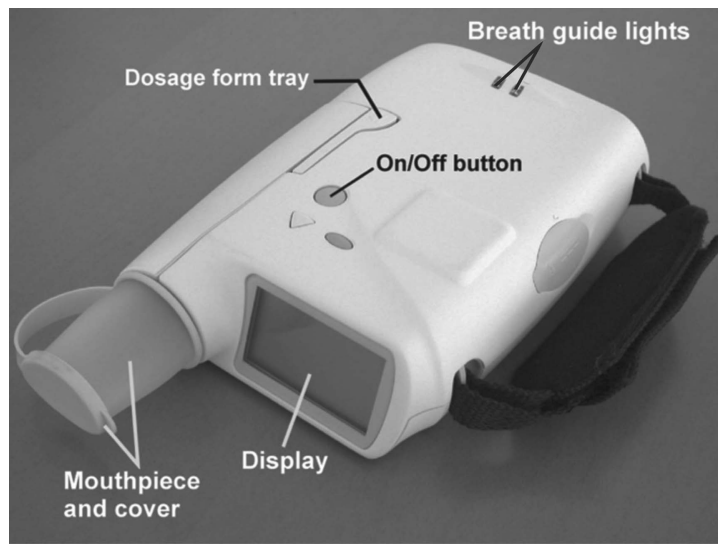

Fig. 6. The AERx PMS drug delivery system. Courtesy Aradigm.

morphine may be metabolized to some extent in the lung, and consequently, droplet size may have considerable influence on efficacy and side effects. In an interesting study in ventilated dogs, nebulized morphine showed a longer duration of action with lower peak serum concentrations relative to intravenous administration. ${ }^{106}$ The authors speculate that this may result in a safer (lower peak level) and more effective (longer duration) route of morphine administration. It should be noted that the inhaled dose $(1.32 \mathrm{mg} / \mathrm{kg})$ was twice that of the intravenous dose $(0.66$ $\mathrm{mg} / \mathrm{kg}$ ), although the authors postulated the doses were comparable because nearly half of the inhaled dose remained in the nebulizer.

Controlled studies in humans are limited. In a clinical trial, nebulized fentanyl for acute pain in a pediatric emergency room was comparable to intravenous administration, although the inhaled dose required was twice that of the intravenous dose. ${ }^{108}$ Fulda et al ${ }^{109}$ compared nebulized and patient-controlled morphine in a blinded RCT in trauma subjects with acute thoracic pain. Subjects receiving nebulized morphine required higher doses but had equivalent pain relief with less sedation. In another study, 2 subjects with sickle cell disease and acute chest syndrome reported $90 \%$ and $40 \%$ pain relief, respectively, with nebulized morphine. ${ }^{110}$ The authors speculate that nebulized morphine might act directly on lung mu receptors and therefore have fewer systemic effects. In contrast, $0.2 \mathrm{mg} / \mathrm{kg}$ morphine administered via nebulization in 22 emergency room subjects with acute severe pain demonstrated no significant pain relief when assessed at 1, 3, 5, and 10 min. ${ }^{111}$ A study examining the bioavailability of nebulized morphine relative to oral and intravenous delivery suggested that the bioavailability of nebulized morphine was only one twentieth that of intravenous morphine and one fifth that of oral morphine. ${ }^{105}$ The authors concluded that nebulized morphine might have a more rapid onset but is a very inefficient means of morphine delivery. 
One of the purported advantages of nebulized narcotics is the effect on dyspnea. Dyspnea is a disturbing symptom in many critically ill and terminal patients. Narcotics administered by a variety of routes are effective in ameliorating dyspnea but at the cost of potential respiratory depression or other undesired effects. Inhaled narcotics are postulated to have a direct effect on intrapulmonary opioid receptors ${ }^{112}$ and thereby require lower doses or have fewer systemic side effects in treating dyspnea. Unfortunately, this has not been substantiated in controlled trials. A review of 18 randomized studies comparing aerosolized and intravenous narcotics demonstrated comparable effectiveness, with neither superior. ${ }^{113}$ This is in contrast to a randomized crossover study by Noseda et $\mathrm{al}^{114}$ showing that neither 10 nor $20 \mathrm{mg}$ of nebulized morphine was any different than a saline placebo as judged by patient dyspnea scales. A similar study using 20 and $40 \mathrm{mg}$ of nebulized morphine produced no improvement in perceived dyspnea or the 6-min walk test relative to placebo. ${ }^{115}$ The specific narcotic being nebulized may also influence efficacy. Seventeen subjects with dyspnea related to terminal cancer pain treated with nebulized hydromorphone reported symptom relief within 15 min without significant adverse effects. ${ }^{116}$ However, there was no comparison group in that study.

A major difficulty in interpreting all studies of aerosolized narcotics is the uncertainty regarding delivered dose. As noted previously, even with a breath-actuated nebulizer, it is estimated that perhaps only $60 \%$ of the dose is actually delivered and how much rains out in the oropharynx, and so on, is unclear (and absorption from mucosal surfaces may also differ). As such, evidence of equivalence or superiority of nebulized versus intravenous is difficult to assess. Aerosolized narcotics may be effective but appear to have less predictable kinetics compared with other modes of delivery. Some of the newer delivery systems (AERx PMS, Staccato fentanyl) produce more predictable pharmacokinetics and may be ideal for rapid administration when intravenous access is not available, and immediate pain relief is desirable. Despite the existence of opioid receptors in the lung, there are no clear differential lung-specific effects (such as on dyspnea) that have been identified to recommend inhaled over intravenous or enteral narcotic administration.

\section{Local Anesthetics}

Nebulized topical anesthetics are also worthy of brief discussion. Nebulized lidocaine has already been mentioned as a potential aerosolized anti-inflammatory in asth$\mathrm{ma}^{78-80}$ and is a very effective topical anesthetic. Nebulized lidocaine has been purported to relieve the pain of nasogastric tube placement, ${ }^{117}$ bronchoscopy, ${ }^{118,119}$ and endotracheal intubation, ${ }^{120}$ although not all studies show ef- ficacy. ${ }^{121,122}$ Tetracaine has been used for a similar purpose but has the potential disadvantage of producing methemoglobinemia with overdose. ${ }^{123}$ The addition of fentanyl to nebulized lidocaine may offer additional benefit. In a study of 45 children undergoing bronchoscopy, Moustafa ${ }^{124}$ compared nebulized lidocaine, lidocaine plus fentanyl, and saline and demonstrated that the combination of lidocaine plus fentanyl resulted in greater hemodynamic stability, fewer episodes of coughing, and less oxygen desaturation. The only adverse effect was a slightly longer recovery time.

Limiting local anesthetic dose is of obvious importance. Toxic levels of lidocaine can provoke seizures, myocardial depression, and dysrhythmias. Tetracaine (and its commonly used product (cetacaine) combined with benzocaine and aminobenzoate) overdose can lead to fatal methemoglobinemia. ${ }^{123}$ The usual dose recommended for inhaled lidocaine is a maximum of $4 \mathrm{mg} / \mathrm{kg}$, but doses as high as $6 \mathrm{mg} / \mathrm{kg}$ have been reported without adverse effects. Systematic comparative studies of different lidocaine concentrations have not been reported, nor has there been any attention to specifics regarding aerosol device or particle size. Because the use of inhaled local anesthetics is primarily for topical analgesia of the nasopharynx and/or oropharynx, larger particle size would seem appropriate when used for this purpose.

\section{Conclusions}

It is possible to aerosolize many different medications with the advantages and disadvantages described previously. The unlabeled use of aerosolized medications is increasing, often without previous study, ${ }^{125}$ and it is important to recognize that aerosolization may change not only drug onset and effect but also dose. Some drugs may lose activity when nebulized, particularly with certain nebulizers, and actual delivered dose may fall short of that intended. Effective dose may be related to particle size, the patient interface with the aerosol device (eg, spacers), and patient coordination or effort. Consequently, dosage must be tailored to the drug's bioavailability when given via the aerosol route. Onset of drug effect may also relate to particle size, and this may be an important consideration with some medications such as narcotics. Wastage and toxicity to those in the immediate environment must also be considered. With nebulized fentanyl, for example, wastage is of little concern because the drug is relatively cheap, but exposure of others in the patient's immediate environment might be a significant consideration.

Aerosolization makes the most sense for drugs where the lung is the primary target organ. Surfactant, inhaled corticosteroids, and increasingly antibiotics (not mentioned in this review) are among the most cogent examples. Drugs must be investigated, however, to determine their bioavail- 


\section{Aerosolized Surfactants, Anti-Inflammatory Drugs, and Analgesics}

ability, pharmacokinetics, pharmacodynamics, and efficacy once aerosolized. Furthermore, the type of aerosol device may impact all of the above. It is imperative that clinicians recognize that aerosolization of a drug may dramatically alter its properties, and investigation should precede acceptance of the aerosol route of drug delivery.

\section{REFERENCES}

1. Hess D. Nebulizers: principles and performance. Respir Care 2000; 45(6):609-622

2. Minocchieri S, Burren JM, Bachmann MA, Stern G, Wildhaber J, Buob S, et al. Development of the premature infant nose throatmodel (PrINT model): an upper airway replica of a premature neonate for the study of aerosol delivery. Pediatr Res 2008;64(2):141146.

3. Dolovich M. Influence of inspiratory flow rate, particle size, and airway caliber on aerosolized drug delivery to the lung. Respir Care 2000;45(11):597-608.

4. Jobe AH. Pulmonary surfactant therapy. NEngl J Med 1993;328(12): 861-868

5. Ware LB, Matthay MA. The acute respiratory distress syndrome. N Engl J Med 2000;342(18):1334-1349.

6. Slutsky AS, Ranieri VM. Ventilator-induced lung injury. N Engl J Med 2013;369(22):2126-2136.

7. Yost C, Soll R. Early versus delayed selective surfactant treatment for neonatal respiratory distress syndrome. Cochrane Database Syst Rev 2002;(2):CD001456.

8. Jobe AH, Bancalari E. Bronchopulmonary dysplasia. Am J Respir Crit Care Med 2001;163(7):1723-1729.

9. Robillard E, Alarie Y, Dagenais-Perusse P, Baril E, Guilbeault A. Microaerosol administration of synthetic $\beta, \gamma$-dipalmitoyl-L- $\alpha$-lecithin in the respiratory distress syndrome: a preliminary report. Can Med Assoc J 1964;90(2):55-57.

10. Chu J, Clements JA, Cotton EK, Klaus MH, Sweet AY, Tooley WH. Neonatal pulmonary ischemia. I. Clinical and physiologic studies. Pediatrics 1967;40(4):Suppl:709-782.

11. Anzueto A, Baughman RP, Guntupalli KK, Weg JG, Wiedemann HP, Raventós AA, Lemaire F, et al. Aerosolized surfactant in adults with sepsis-induced acute respiratory distress syndrome. N Engl J Med 1996;334(22):1417-1421.

12. Enhörning G, Grossman G, Robertson B. Tracheal deposition of surfactant before the first breathe. Am Rev Respir Dis 1973;107(6): 921-927.

13. Fujiwara T, Chida S, Watabe Y, Maeta H, Morita T, Abe T. Artificial surfactant therapy in hyaline-membrane disease. Lancet 1980; 315(8159):55-59.

14. Morley CJ, Miller N, Bangham AD, Davis JA. Dry artificial lung surfactant and its effect on very premature babies. Lancet 1981; 317(8211):64-68

15. Pillow JJ, Minocchieri S. Innovation in surfactant therapy. II. Surfactant administration by aerosolization. Neonatology 2012;101(4): 337-344.

16. Sun Y, Yang R, Zhong JG, Fang F, Jiang JJ, Liu M, Lu J. Aerosolized surfactant generated by a novel noninvasive apparatus reduced lung injury in rats. Crit Care 2009;13(2):R31.

17. Rubin BK. Pediatric aerosol therapy: new devices and new drugs. Respir Care 2011;56(9):1411-1421; discussion 1421-1423

18. Lewis JF, Tabor B, Ikegami M, Jobe AH, Joseph M, Absolom D. Lung function and surfactant distribution in saline-lavaged sheep given instilled vs nebulized surfactant. J Appl Physiol 1993;74(3): 1256-1264.
19. Lewis JF, Goffin J, Yue P, McCaig LA, Bjarneson D, Veldhuizen RA. Evaluation of exogenous surfactant treatment strategies in an adult model of acute lung injury. J Appl Physiol 1996;80(4):11561164.

20. Fok TF, al-Essa M, Dolovich M, Rasid F, Kirpalani H. Nebulization of surfactants in an animal model of neonatal respiratory distress. Arch Dis Child Fetal Neonatal Ed 1998;78(1):F3-F9.

21. Lampland AL, Wolfson MR, Mazela J, Henderson C, Gregory TJ, Meyers P, et al. Aerosolized KL4 surfactant improves short-term survival and gas exchange in spontaneously breathing newborn pigs with hydrochloric acid-induced acute lung injury. Pediatr Pulmonol 2014;49(5):482-489.

22. Ruppert C, Kuchenbuch T, Boensch M, Schmidt S, Mathes U, Hillebrand V, et al. Dry powder aerosolization of a recombinant surfactant protein C-based surfactant for inhalative treatment of the acutely inflamed lung. Crit Care Med 2010;38(7):1584-1591.

23. Dijk PH, Heikamp A, Bambang Oetomo S. Surfactant nebulization prevents the adverse effects of surfactant therapy on blood pressure and cerebral blood flow in rabbits with severe respiratory failure. Intensive Care Med 1997;23(10):1077-1081.

24. Schermuly RT, Günther A, Weissmann N, Ghofrani HA, Seeger W, Grimminger F, Walmrath D. Differential impact of ultrasonically nebulized versus tracheal-instilled surfactant on ventilation-perfusion $(\dot{\mathrm{V}} \mathrm{A} / \mathrm{Q})$ mismatch in a model of acute lung injury. Am J Respir Crit Care Med 2000;161(1):152-159.

25. Rey-Santano C, Mielgo VE, Andres L, Ruiz-del-Yerro E, Valls-iSoler A, Murgia X. Acute and sustained effects of aerosolized vs. bolus surfactant therapy in premature lambs with respiratory distress syndrome. Pediatr Res 2013;73(5):639-646.

26. Wagner MH, Amthauer H, Sonntag J, Drenk F, Eichstädt HW, Obladen M. Endotracheal surfactant atomization: an alternative to bolus instillation? Crit Care Med 2000;28(7):2540-2544.

27. Jorch G, Hartl H, Roth B, Kribs A, Gortner L, Schaible T, et al. Surfactant aerosol treatment of respiratory distress syndrome in spontaneously breathing premature infants. Pediatr Pulmonol 1997; 24(3):222-224.

28. Arroe M, Pedersen-Bjergaard L, Albertsen P, Bode S, Greisen G, Jonsbo $\mathrm{F}$, et al. Inhalation of aerosolized surfactant (Exosurf) to neonates treated with nasal continuous positive airway pressure. Prenat Neonat Med 1998;3(3):346-352.

29. Berggren E, Liljedahl M, Winbladh B, Andreasson B, Curstedt T, Robertson B, Schollin J. Pilot study of nebulized surfactant therapy for neonatal respiratory distress syndrome. Acta Paediatr 2000; 89(4):460-464.

30. Finer NN, Merritt TA, Bernstein G, Job L, Mazela J, Segal R. An open label, pilot study of Aerosurf combined with nCPAP to prevent RDS in preterm neonates. J Aerosol Med Pulm Drug Deliv 2010;23(5):303-309.

31. Willson DF, Egan EE, Notter R. Exogenous surfactant in the pediatric patient. In: Rimensberger PC. Neonatal and pediatric mechanical ventilation: from basics to clinical practice. Berlin: Springer-Verlag; 2014.

32. Anzueto A, Jubran A, Ohar JA, Piquette CA, Rennard SI, Colice G, et al. Effects of aerosolized surfactant in patients with stable chronic bronchitis. JAMA 1997;278(17):1426-1431.

33. Corcoran TE, Thomas KM, Garoff S, Tilton RD, Przybycien TM, Pilewski JM. Imaging the postdeposition dispersion of an inhaled surfactant aerosol. J Aerosol Med Pulm Drug Deliv 2012;25(5): 290-296.

34. Griese M, Bufler P, Teller J, Reinhardt D. Nebulization of a bovine surfactant in cystic fibrosis: a pilot study. Eur Respir J 1997;10(9): 1989-1994.

35. Strüber M, Cremer J, Harringer W, Hirt SW, Costard-Jäckle A, Haverich A. Nebulized synthetic surfactant in reperfusion injury 


\section{Aerosolized Surfactants, Anti-Inflammatory Drugs, and Analgesics}

after single lung transplantation. J Thorac Cardiovasc Surg 1995; 110(2):563-564.

36. Babu KS, Woodcock DA, Smith SE, Staniforth JN, Holgate ST, Conway JH. Inhaled synthetic surfactant abolishes the early allergen-induced response in asthma. Eur Respir J 2003;21(6):10461049 .

37. Kurashima K, Ogawa H, Ohka T, Fujimura M, Matsuda T, Kobayashi $\mathrm{T}$. A pilot study of surfactant inhalation in the treatment of asthma attack. Arerugi 1991;40(2):160-163.

38. Oetomo SB, Dorrepaal C, Bos H, Gerritsen J, van der Mark TW, Koëter GH, van Aalderen WM. Surfactant nebulization does not alter airflow obstruction and bronchial responsiveness to histamine in asthmatic children. Am J Respir Crit Care Med 1996;153(3): $1148-1152$.

39. Winkler C, Hohlfeld JM. Surfactant and allergic airway inflammation. Swiss Med Wkly 2013;143:w13818.

40. Willson DF, Thomas NJ, Tamburro R, Truemper E, Truwit J, Conaway $\mathrm{M}$, et al. Pediatric calfactant in acute respiratory distress syndrome trial. Pediatr Crit Care Med 2013;14(7):657-665.

41. de Benedictis FM, Bush A. Corticosteroids in respiratory diseases in children. Am J Respir Crit Care Med 2012;185(1):12-23.

42. Yeh TF, Lin YJ, Lin HC, Huang CC, Hsieh WS, Lin CH, Tsai CH. Outcomes at school age after postnatal dexamethasone therapy for lung disease of prematurity. N Engl J Med 2004;350(13):13041313.

43. Cheong JL, Burnett AC, Lee KJ, Roberts G, Thompson DK, Wood SJ, et al. Association between postnatal dexamethasone for treatment of bronchopulmonary dysplasia and brain volumes at adolescence in infants born prematurely. J Pediatr 2014;164(4):737.e1743.e1.

44. Lai HC, FitzSimmons SC, Allen DB, Kosorok MR, Rosenstein BJ, Campbell PW, Farrell PM. Risk of persistent growth impairment after alternate-day prednisone treatment in children with cystic fibrosis. N Engl J Med 2000;342(12):851-859.

45. Abroug F, Ouanes-Besbes L, Fkih-Hassen M, Ouanes I, Ayed S, Dachraoui $\mathrm{F}$, et al. Prednisone in COPD exacerbation requiring ventilator support: an open-label randomized evaluation. Eur Respir J 2014;43(3):717-724.

46. Leuppi JD, Schuetz P, Bingisser R, Bodmer M, Briel M, Drescher $\mathrm{T}$, et al. Short-term vs. conventional glucocorticoid therapy in acute exacerbations of chronic obstructive pulmonary disease: the REDUCE randomized clinical trial. JAMA 2013;309(21):22232231.

47. Barnes PJ. Efficacy of inhaled corticosteroids in asthma. J Allergy Clin Immunol 1998;102(4):531-538.

48. Pauwels RA, Pedersen S, Busse WW, Tan WC, Chen YZ, Ohlsson $\mathrm{SV}$, et al. Early intervention with budesonide in mild persistent asthma: a randomized, double-blind trial. Lancet 2003;361(9363): 1071-1076.

49. Suissa S, Ernst P, Benayoun S, Baltzan M, Cai B. Low-dose inhaled corticosteroids and the prevention of death from asthma. N Engl J Med 2000;343(5):332-336.

50. Kelly HW, Sternberg AL, Lescher R, Fuhlbrigge AL, Williams P, Zeiger RS, et al. Effect of inhaled glucocorticoids in childhood on adult height. N Engl J Med 2012;367(10):904-912.

51. Boushey HA, Sorkness CA, King TS, Sullivan SD, Fahy JV, Lazarus $\mathrm{SC}$, et al. Daily versus as-needed corticosteroids for mild persistent asthma. N Engl J Med 2005;352(15):1519-1528.

52. Chauhan BF, Chartrand C, Ducharme FM. Intermittent versus daily inhaled corticosteroids for persistent asthma in children and adults. Cochrane Database Syst Rev 2012;(12):CD009611.

53. Yang IA, Fong K, Sim EH, Black PN, Lasserson TJ. Inhaled corticosteroids for stable chronic obstructive pulmonary disease. Cochrane Database Syst Rev 2007;(2):CD002991.
54. Cole CH, Colton T, Shah BL, Abbasi S, MacKinnon BL, Demissie S, Frantz ID. Early inhaled glucocorticoid therapy to prevent bronchopulmonary dysplasia. N Engl J Med 1999;340(13):1005-1010.

55. Adcock IM, Gilbey T, Gelder CM, Chung KF, Barnes PJ. Glucocorticoid receptor localization in normal and asthmatic lung. Am J Respir Crit Care Med 1996;154(3):771-782.

56. Leach C, Colice GL, Luskin A. Particle size of inhaled corticosteroids: does it matter? J Allergy Clin Immunol 2009;124(6 Suppl): S88-S93

57. Gross G, Thompson PJ, Chervinsky P, Vanden Burgt J. Hydrofluoroalkane-134a beclomethasone dipropionate, $400 \mu \mathrm{g}$, is as effective as chlorofluorocarbon beclomethasone dipropionate $800 \mu \mathrm{g}$, for the treatment of moderate asthma. Chest 1999;115(2):343-351.

58. Davies RJ, Stampone P, O'Connor BJ. Hydrofluoroalkane-134a beclomethasone dipropionate extrafine aerosol provides equivalent asthma control to chlorofluorocarbon beclomethasone dipropionate at approximately half the total daily dose. Respir Med 1998;92(Suppl A):23-31.

59. Corren J, Nelson H, Greos LS, Bensch G, Goldstein M, Wu J, et al. Effective control of asthma with hydrofluoroalkane flunisolide delivered as an extrafine aerosol in asthma patients. Ann Allery Asthma Immunol 2001;87(5):405-411.

60. Amirav I, Newhouse MT, Minocchieri S, Castro-Rodriguez JA, Schüepp KG. Factors that affect the efficacy of inhaled corticosteroids for infants and young children. J Allergy Clin Immunol 2010; 125(6):1206-1211.

61. Hirst C, Calingaert B, Stanford R, Castellsague J. Use of longacting beta-agonists and inhaled steroids in asthma: a meta-analysis of observational studies. J Asthma 2010;47(4):439-446.

62. Global Initiative for Asthma (GINA). GINA Report, Global Strategy for Asthma Management and Prevention, updated December 2012. http://www.ginasthma.org/uploads/users/files/GINA Report_2012.pdf. Accessed March 12, 2014.

63. Cazzola M, Page C, Matera MG. Long-acting muscarinic receptor antagonists for treatment of respiratory disease. Pulm Pharmacol Ther 2013;26(3):307-317.

64. Peters SP, Kunselman SJ, Icitovic N, Moore WC, Pascual R, Ameredes BT, et al. Tiotropium bromide step-up therapy for adults with uncontrolled asthma. N Engl J Med 2010;363(18):1715-1726.

65. Kerstjens HA, Engel M, Dahl R, Paggiaro P, Beck E, Vandewalker $\mathrm{M}$, et al. Tiotropium in asthma poorly controlled with standard combination therapy. N Engl J Med 2012;367(13):1198-1207.

66. Fuhr R, Magnussen H, Sarem K, Llovera AR, Kirsten AM, Falqués M, et al. Efficacy of aclidinium bromide $400 \mu$ gram twice daily compared with placebo and tiotropium in patients with moderate to severe COPD. Chest 2012;141(3):745-752.

67. Singh S, Loke YK, Enright PL, Furberg CD. Mortality associated with tiotropium mist inhaler in patients with chronic obstructive pulmonary disease: systemic review and meta-analysis of randomized controlled trials. BMJ 2011;342:d3215.

68. Wise RA, Anzueto A, Cotton D, Dahl R, Devins T, Disse B, et al. Tiotropium Respimat Inhaler and the risk of death in COPD. N Engl J Med 2013;369(16):1491-1501.

69. Tashkin DP, Ferguson GT. Combination bronchodilator therapy in the management of chronic obstructive pulmonary disease. Respir Res 2013;14(1):49

70. Powell CV. The role of magnesium sulfate in acute asthma: does route of administration make a difference? Curr Opin Pulm Med 2014;20(1):103-108.

71. Hughes R, Goldkorn A, Masoli M, Weatherall M, Burgess C, Beasley $\mathrm{R}$. Use of isotonic nebulized magnesium sulphate as an adjuvant to salbutamol in treatment of severe asthma in adults: randomized placebo-controlled trial. Lancet 2003;361(9375):2114-2117. 


\section{Aerosolized Surfactants, Anti-Inflammatory Drugs, and Analgesics}

72. Goodacre S, Cohen J, Bradburn M, Stevens J, Gray A, Benger J, Coats $\mathrm{T}$. The $3 \mathrm{Mg}$ trial: a randomized controlled trial of intravenous or nebulized magnesium sulphate versus placebo in adults with acute severe asthma. Health Technol Assess 2014;18(22):1-168.

73. Powell C, Kolamunnage-Dona R, Lowe J, Boland A, Petrou S, Doull I, et al. Magnesium sulphate in acute severe asthma in children (MAGNETIC): a randomized placebo-controlled trial. Lacet Respir Med 2013;1(4):301-308.

74. Mahajan P, Haritos D, Rosenberg N, Thomas R. Comparison of nebulized magnesium sulfate plus albuterol to nebulized albuterol plus saline in children with acute exacerbations of mild to moderate asthma. J Emerg Med 2004;27(1):21-25.

75. Storms W, Kaliner MA. Cromolyn sodium: fitting an old friend into current asthma treatment. J Asthma 2005;42(2):79-89.

76. Van der Wouden JC, Uijen JH, Bernsen RM, Tasche MJ, de Jongste JC, Ducharme FM. Inhaled sodium cromoglycate for asthma in children. Cochrane Database Syst Rev 2008;(4):CD002173.

77. Keller M, Schierholz. Have inadequate delivery systems hampered the clinical success of inhaled disodium cromoglycate? Time for reconsideration. Expert Opin Drug Deliv 2011;8(1):1-17.

78. Ohnishi T, Kita H, Mayeno AN, Okada S, Sur S, Broide DH, Gleich GJ. Lidocaine in bronchoalveolar lavage fluid (BALF) is an inhibitor of eosinophil-active cytokines. Clin Exp Immunol 1996; 104(2):325-331.

79. Okada S, Hagan JB, Kato M, Bankers-Fulbright JL, Hunt LW, Gleich GJ, Kita H. Lidocaine and its analogues inhibit IL-5-mediated survival and activation of human eosinophils. J Immunol 1998; 160(8):4010-4017

80. Hunt LW, Frigas E, Butterfield JH, Kita H, Blomgren J, Dunnette SL, et al. Treatment of asthma with nebulized lidocaine: a randomized, placebo-controlled trial. J Allergy Clin Immunol 2004;113(5): 853-859

81. Abuan T, Yeager M, Montgomery AB. Inhaled lidocaine for the treatment of asthma: lack of efficacy in two double-blind, randomized, placebo-controlled clinical studies. J Aerosol Med Pulm Drug Deliv 2010;23(6):381-388.

82. Mitruka SN, Won A, McCurry KR, Zeevi A, McKaveney T, Venkataramanan $\mathrm{R}$, et al. In the lung aerosol cyclosporine provides a regional concentration advantage over intramuscular cyclosporine. J Heart Lung Transplant 2000;19(10):969-975.

83. Dowling RD, Zenati M, Burckart GJ, Yousem SA, Schaper M, Simmons RL, et al. Aerosolized cyclosporine as single-agent immunotherapy in canine lung allografts. Surgery 1990;108(2):198204.

84. Iacono AT, Corcoran TE, Griffith BP, Grgurich WF, Smith DA, Zeevi A, et al. Aerosol cyclosporine therapy in lung transplant recipients with bronchiolitis obliterans. Eur Respir J 2004;23(3): 384-390.

85. Iacono AT, Keenan RJ, Duncan SR, Smaldone GC, Dauber JH, Paradis IL, et al. Aerosolized cyclosporine in lung recipients with refractory chronic rejection. Am J Respir Crit Care Med 1996; 153(4):1451-1455

86. Iacono AT, Johnson BA, Grgurich WF, Youssef JG, Corcoran TE, Seiler DA, et al. A randomized trial of inhaled cyclosporine in lung-transplant recipients. N Engl J Med 2006;354(2):141-150.

87. Rohatagi S, Calic F, Harding N, Ozoux ML, Bouriot JP, Kirkesseli $\mathrm{S}$, et al. Pharmacokinetics, pharmacodynamics, and safety of inhaled cyclosporine A (ADI628) after single and repeated administration in health male and female subjects and asthmatic patients. J Clin Pharmacol 2000;40(11):1211-1226.

88. Ahmed T, Gonzalez BJ, Danta I. Prevention of exercise-induced bronchoconstriction by inhaled low-molecular-weight heparin. Am J Respir Crit Care Med 1999;160(2):576-581.
89. Stelmach I, Jerzynska J, Stelmach W, Majak P, Brzozowska A, Gorski P, Kuna P. The effect of inhaled heparin on airway responsiveness to histamine and leukotriene $\mathrm{D}_{4}$. Allergy Asthma Proc 2003;24(1):59-65.

90. Walker PA, Shah SK, Letourneau PA, Allison ND, Cox CS. Treatment of plastic bronchitis using serial flexible bronchoscopy and aerosolized heparin therapy. Eur J Pediatr Surg 2013;23(2):157160.

91. Miller AC, Elamin EM, Suffredini AF. Inhaled anticoagulation regimens for the treatment of smoke inhalation-associated acute lung injury: a systematic review. Crit Care Med 2014;42(2):413419.

92. Desai MH, Mlcak R, Richardson J, Nichols R, Herndon DN. Reduction in mortality in pediatric patients with inhalation injury with aerosolized heparin/N-acetylcystine therapy. J Burn Care Rehabil 1998;19(3):210-212.

93. Miller AC, Rivero A, Ziad S, Smith DJ, Elamin EM. Influence of nebulized unfractionated heparin and $\mathrm{N}$-acetylcysteine in acute lung injury after smoke inhalation injury. J Burn Care Res 2009;30(2): 249-256.

94. Rivero A, Elamin E, Nguyen V, Cruse W, Smith D. Can nebulized heparin and $\mathrm{N}$-acetylcysteine reduce acute lung injury after inhalation lung insult? Chest 2007;132(4):565.

95. Kanoh S, Tanabe T, Rubin BK. Dapsone inhibits IL-8 secretion from human bronchial epithelial cells stimulated with lipopolysaccharide and resolves airway inflammation in the ferret. Chest 2011; 140(4):980-990.

96. Nuhoğlu C, Yaşar Kiliç M, Ceran O. Effectiveness of inhaled furosemide added to nebulized salbutamol in children with acute asthma. Allergol Immunopathol 2006;34(2):54-58.

97. Stigliani M, Aquino RP, Del Gaudio P, Mencherini T, Sansone F, Russo P. Non-steroidal anti-inflammatory drug for pulmonary administration: design and investigation of ketoprofen lysinate fine dry powder. Int J Pharm 2013;448(1):198-204.

98. Busse WW, Middleton E, Storms W, Dockhorn RJ, Chu TJ, Grossman J, et al. Corticosteroid-sparing effect of azelastine in the management of bronchial asthma. Am J Respir Crit Care Med 1996; 153(1):122-127.

99. Lauterbach R, Szymura-Oleksiak J, Pawlik D, Warchoł J, LisowskaMiszczyk I, Rytlewski K. Nebulized pentoxifylline for prevention of bronchopulmonary dysplasia in very low birth weight infants: a pilot clinical study. J Matern Fetal Neonatal Med 2006;19(7):433438.

100. Diaz KT, Skaria S, Harris K, Solomita M, Lau S, Bauer K, et al Delivery and safety of inhaled interferon- $\gamma$ in idiopathic pulmonary fibrosis. J Aerosol Med Pulm Drug Deliv 2012;25(2):79-87.

101. Wax PM, Becker CE, Curry SC. Unexpected "gas" casualties in Moscow: a medical toxicology perspective. Ann Emerg Med 2003; 41(5):700-705.

102. Dershwitz M, Walsh JL, Morishige RJ, Connors PM, Rubsamen RM, Shafer SL, Rosow CE. Pharmacokinetics and pharmacodynamics of inhaled versus intravenous morphine in healthy volunteers. Anesthesiology 2000;93(3):619-628.

103. Krajnik M, Podolec Z, Siekierka M, Sykutera M, Pufal E, Sobanski $\mathrm{P}$, et al. Morphine inhalation by cancer patients: a comparison of different nebulization techniques using pharmacokinetic, spirometric, and gasometric parameters. J Pain Symptom Manage 2009; 38(5):747-757.

104. MacLeod DB, Habib AS, Ikeda K, Spyker DA, Cassella JV, Ho KY, Gan TJ. Inhaled fentanyl aerosol in healthy volunteers: pharmacokinetics and pharmacodynamics. Anesth Analg 2012;115(5): 1071-1077. 
105. Masood AR, Thomas SH. Systemic absorption of nebulized morphine compared with oral morphine in healthy subjects. Br J Clin Pharmacol 1996;41(3):250-252

106. Xu X, Wang X, Ge W, Pan L, Zheng M. The pharmacokinetics of inhaled morphine delivered by an ultrasonic nebulizer in ventilated dogs. J Aerosol Med Pulm Drug Deliv 2012;25(1):41-46.

107. Thipphawong JB, Babul N, Morishige RJ, Findlay HK, Reber KR, Millward GJ, Otulana BA. Analgesic efficacy of inhaled morphine in patients after bunionectomy surgery. Anesthesiology 2003;99(3): 693-700.

108. Miner JR, Kletti C, Herold M, Hubbard D, Biros MH. Randomized clinical trial of nebulized fentanyl citrate versus IV fentanyl citrate in children presenting to the emergency department with acute pain. Acad Emerg Med 2007;14(10):895-898.

109. Fulda GJ, Giberson F, Fagraeus L. A prospective randomized trial of nebulized morphine compared with patient-controlled analgesia morphine in the management of acute thoracic pain. J Trauma 2005;59(2):383-388; discussion 389-390.

110. Ballas SK, Viscusi ER, Epstein KR. Management of acute chest wall sickle cell pain with nebulized morphine. Am J Hematol 2004; 76(2):190-191.

111. Bounes V, Ducassé JL, Bona AM, Battefort F, Houze-Cerfon CH, Lauque D. Nebulized morphine for analgesia in an emergency setting. J Opioid Manag 2009;5(1):23-26.

112. Zebraski SE, Kochenash SM, Raffa RB. Lung opioid receptors: pharmacology and possible target for nebulized morphine in dyspnea. Life Sci 2000;66(23):2221-2231.

113. Jennings AL, Davies AN, Higgins JP, Broadley K. Opioids for the palliation of breathlessness in terminal illness. Cochrane Database System Rev 2001;(4)CD002066.

114. Noseda A, Carpiaux JP, Markstein C, Meyvaert A, de Maertelaer V. Disabling dyspnea in patients with advanced disease: lack of effect of nebulized morphine. Eur Respir J 1997;10(5):10791083

115. Jankelson D, Hosseini K, Mather LE, Seale JP, Young IH. Lack of effect of high doses of inhaled morphine on exercise endurance in chronic obstructive pulmonary disease. Eur Respir J 1997;10(10): 2270-2274.

116. Charles MA, Reymond L, Israel F. Relief of incident dyspnea in palliative cancer patients: a pilot, randomized, controlled trial comparing nebulized hydromorphone, systemic hydromorphone, and nebulized saline. J Pain Symptom Manage 2008;36(1): 29-38.

117. Cullen L, Taylor D, Taylor S, Chu K. Nebulized lidocaine decreases the discomfort of nasogastric tube insertion: a randomized, double-blind trial. Ann Emerg Med 2004;44(2):131-137.

118. Graham DR, Hay JG, Clague J, Nisar M, Earis JE. Comparison of three different methods used to achieve local anesthesia for fiberoptic bronchoscopy. Chest 1992;102(3):704-707.

119. Gjonaj ST, Lowenthal DB, Dozor AJ. Nebulized lidocaine administered to infants and children undergoing flexible bronchoscopy. Chest 1997;112(6):1665-1669.

120. Kundra P, Kutralam S, Ravishankar M. Local anaesthesia for awake fibreoptic nasotracheal intubation. Acta Anaesthesiol Scand 2000; 44(5):511-516.

121. Stolz D, Chhajed PN, Leuppi J, Pflimlin E, Tamm M. Nebulized lidocaine for flexible bronchoscopy: a randomized, double-blind, placebo-controlled trial. Chest 2005;128(3):1756-1760.

122. Babl FE, Goldfinch C, Mandrawa C, Crellin D, O'Sullivan R, Donath S. Does nebulized lidocaine reduce the pain and distress of nasogastric tube insertion in young children? A randomized, double-blind, placebo-controlled trial. Pediatrics 2009;123(6):15481555 .

123. Guay J. Methemoglobinemia related to local anesthetics: a summary of 242 episodes. Anesth Analg 2009;108(3):837-845.

124. Moustafa MA. Nebulized lidocaine alone or combined with fentanyl as a premedication to general anesthesia in spontaneously breathing pediatric patients undergoing rigid bronchoscopy. Paediatr Anaesth 2013;23(5):429-434.

125. Shirk MB, Donahue KR, Shirvani J. Unlabeled uses of nebulized medications. Am J Health Syst Pharm 2006;63(18):1704-1716.

\section{Discussion}

Hess: Maybe a comment more than a question, but something that struck me in your presentation and in Marcos' [Restrepo] presentation, which I think is an important take-home message from the entire conference, is that a nebulizer is not a nebulizer is not a nebulizer. I think that many of us have an albuterol type of mentality where we take any old $50 \phi$ nebulizer off the shelf, we put whatever we want to aerosolize into the device, we have the patient use the device, and we expect the desired outcome. But I think it becomes very complicated, particularly for some of these newer formulations that may require a specific type of device in order for the formulation to be appropriately aerosolized and delivered into the correct spot of the respi- ratory tract where it's likely to have an effect.

Willson: Well Dean, speaking as a pediatric and intensive care physician, I had no understanding of that before being asked to give this talk. I frankly thought a nebulizer was a nebulizer. Unfortunately, you RTs [respiratory therapists] are being asked to do things by physicians who may not know this. I consider myself a pretty good intensivist, and I didn't really have an understanding of that. In looking through the literature, and Lord knows how many papers I read, it astounds me that sometimes in the research it isn't given consideration either. The whole issue of narcotics, for example. You read the literature, and nobody talks about the aerosol device or the size of the particles, all the things we now know are important. So I couldn't agree more that it's an important point to be made and emphasized.

* Fink: Great presentation, and I'd like to echo Dean's comments. Back to surfactant, there were some early studies with jet nebulizers that compared protein levels pre- and post-nebulization, and it appeared that while the phospholipids made it out, only about $2-3 \%$ of the original level of proteins made it out of the nebulizer, suggesting there was a cotton-candy-type effect within the nebulizer. Some of the newer technologies are able to get the proteins out. So it could be that using a finer vibrating mesh actually gets a better result than using jet nebulizers because if you remove the proteins from the surfactant, then it's just like the surfactants such as Exosurf without proteins, right? 
Willson: Right.

$\dagger$ MacIntyre: What's the cottoncandy effect?

* Fink: The proteins kind of stick to the plastics when you run the gas through, which is how they described it. They believe they were getting adhesion of the protein to the walls of the nebulizer.

Willson: In Lewis' study ${ }^{1}$ that I mentioned, with the whole-lung surfactant BLES [bovine lung extract surfactant], that's what they speculated happened: that the proteins are inactivated or lost in the process of aerosolization. Again, if you look through that, I think I mentioned at least 7 or 8 different surfactants. Of course, it's important to realize that not all surfactants are the same. So it's not just that some get lost, it's that some don't start with it.

* Fink: And pouring anything into a nebulizer is just not good practice. With inhalation toxicity, you should at least know that it's been used with some level of safety, and we're way too cavalier at pouring things into nebulizers without knowing whether they change the drug or if it's really safe for inhalation.

Berlinski: Could you comment on the use of surfactant delivered during fiberoptic bronchoscopy? We are asked sometimes by the intensivists to directly instill with the fiberoptic bronchoscope in severe ARDS and some patients who are even on ECMO [extracorporeal membrane oxygenation], and usually, my response is that it's probably cheaper to put a nasogastric tube through the ETT [endotracheal tube] and just flush it because that's what happens when you do it with the bronchoscope. Could you comment as to whether there's any value to the procedure?
Willson: Actually, there was a study with KL4 surfactant that was stopped for futility because the study design was a randomized prospective lobeby-lobe instillation into the airway. For kids who are on ECMO I wouldn't have a problem because they are supported, but I'd say it's a bad idea to put a bronchoscope in a child or baby with a 3.5- or 4.0-mm ETT and try to inject directly. If you obstruct the airway with the bronchoscope, you'll do it doubly with the surfactant. In adults, it's less of an issue, and they've tried that approach. As I said, that study never made it to publication. They were about 50 or 60 subjects into it with too many side effects and too many adverse consequences, and it didn't seem to make any difference. Surfactant by its very nature spreads rapidly. So, to me, it never made much sense to take that approach. No, I wouldn't recommend it. For those kids whom you really feel surfactant instillation might be helpful, I would put it down the ETT and change position to have gravity help you get it distributed.

Corcoran: Just a comment. We spent the last few years trying to nebulize surfactant to actually use it as a spreading agent for other drugs. The nebulization is particularly important for some of these surfactants because they exist as aggregates. So what we found was that, in some cases, the nebulization can actually help the function, at least as a spreading agent, because it can actually shatter some of these big-aggregate molecules that may exist. So there are definite opportunities for aerosolization to affect the activity of the drug. I always thought it was very interesting that Discovery Labs used a completely different aerosolization mechanism for their inhaled product. I was never quite clear on why, and I was wondering whether you had any ideas as to what they were using and why?
Willson: They have this capillary aerosol generator, and again, I would not even profess to be nearly sophisticated enough to comment on that. They seem to think it's terrific. They have looked at the activity of their KL4 surfactant after aerosolization with that device, and it retains its activity. The particle size is appropriate in the 1-2- $\mu \mathrm{m}$ range, so in theory, it should fulfill the requirements for that ideal coupling of surfactant and aerosolizer, but that's all I know, frankly.

Restrepo: I was interested when you said inhaled corticosteroids and COPD. There are so many data for inhaled corticosteroids and asthma. What is specific to patients with COPD that they are likely to develop pneumonia?

Willson: Well, I'm a pediatrician, so COPD is not an area that I know very much about. But the data are pretty clear that there's an increased incidence of pneumonia and hospitalization with use of inhaled corticosteroids, but why? I don't know.

$\dagger$ MacIntyre: The most widely reported study of inhaled corticosteroids and COPD is probably the TORCH trial, ${ }^{2}$ which was sponsored by GlaxoSmithKline and looked at inhaled corticosteroids, inhaled long-acting $\beta_{2}$ agonists, and the combination of those versus placebo. Inhaled corticosteroid by itself seemed to reduce exacerbations, but in combination with longacting $\beta_{2}$ agonists, exacerbation reductions were more evident. That is why inhaled corticosteroids and inhaled corticosteroid/long-acting $\beta_{2}$ agonist medications are on all the guidelines. The issue with an increased pneumonia risk using these drugs in this study I find very confusing. Why are exacerbations reduced but pneumonias increased? That seems to be a contradiction, and I've never heard a good explanation for this. One explanation that might make some sense is that COPD exacerbations were very 
carefully quantified and recorded on the data report forms. Pneumonia, on the other hand, was simply a checkbox that the clinician investigator filled out. So maybe the methodology for reporting exacerbations and the methodology for reporting pneumonias created 2 different outcomes. I don't know whether that's the answer or not. Nevertheless, that was a long-winded way of saying there is evidence for inhaled corticosteroids in the management of COPD, and it's in the guidelines. It uses what I think is the very important end point of exacerbation reduction.

\section{Willson: Thank you.}

Laube: I had a question about surfactant as well. Suppose you could show that the powder formulation that worked in rabbits and mice in your slides would actually work in infants? Do you have any idea how long the effects would last and how often you would have to re-treat with aerosolized surfactant if it worked?

Willson: As you may not know, even with instillation, there's a lot of debate about how often to re-treat. A good aspect to that is that if you needed to re-treat, you'd just basically nebulize it again with the babies breathing spontaneously. Other than expense, I'm not sure it would be a big problem. The only side effect that Finer et $\mathrm{al}^{3}$ saw and that has been reported with aerosolized surfactant (not with the powder because, as far as I know, that hasn't been studied in kids, but with the KL4 surfactant) was an increase in secretions, but that's pretty much the only untoward effect from aerosolization. That's my way of saying that if you had to re-treat, you would probably base it on clinical symptomatology...tachypnea, maybe $\mathrm{x}$-ray changes.

DiBlasi: Beth, as a follow up to your question, I think that there are huge limitations to giving powder-inhaler surfactant formulations with infants.
First of all, they need to be able to activate the device, and I don't know of any formulations that use devices that are sensitive enough or that are designed to be used in line with the therapies that infants commonly receive (ie, nasal CPAP). Nasal CPAP requires humidity, and with a powder inhaler in the presence of humidity, there is hygroscopic accumulation or clumping, which could obstruct the valves of these systems. So although it seems like something that may have potential benefit in those patients, it's going to be difficult. It's all about the device we're delivering the drug with and how we're delivering it.

Willson: I think that's a good point to make. There's this one animal model where they humidified the powder in a secondary chamber and managed to maintain adequate size. Obviously, the particle became a little bit bigger, but it was still within the respirable range. So there is a way to perhaps accomplish that, but it is surprising how complicated it is.

DiBlasi: With that being said, with the limitations of the devices being used in line with different nasal CPAP or noninvasive respiratory support modalities, which most neonates are being supported with nowadays, nobody really wants to take them off due to clinical deterioration. I foresee the future of nebulized or aerosolized surfactant for neonates as kind of grim. The reason why is, as Dean mentioned earlier, a nebulizer is not a nebulizer-not all nebulizers are created equal. So it's very difficult to provide a drug like that using a nebulizer that's nebulizing throughout the respiratory cycle and expect that you're going to get a lot of drug delivered to the baby. I think many people have circumvented that and have placed thin catheters down into the airway while the baby's still on CPAP, ${ }^{4}$ or they deliver a bolus of surfactant to the babies as they present at the perineum during birth. There is also another minimally invasive method described in the literature, ${ }^{5}$ wherein a bolus of surfactant is delivered retropharyngeally to babies as they present during birth, and with the first breath, the drug can be aspirated into the lungs. Evidence from animal and observational human studies suggests that pharyngeal instillation of surfactant before the first breath is potentially safe and feasible and may be effective. I'm curious about your thoughts on just dumping it down the airway in the absence of an ETT.

Willson: There's certainly a risk in intubating a small baby; the risk is fairly small, but I do worry about it. I showed you in that rabbit model ${ }^{6}$ the consequences of instillation of a large volume of fluid down the airway in a very unstable small baby with a very fragile brain and germinal matrix. I'm not as pessimistic, though. Ariel, I think you have some experience using aerosolized surfactant?

Berlinski: Yes, some clinical experience, but it's not very good. I just wanted to make the point that given the weight of the bronchoscope, it doesn't help much. It's more for older patients and not neonates.

Willson: I think Rob [DiBlasi] brings up some problems, but we'll see. It's subject to investigation.

Restrepo: You suggested that surfactant should be used before respiratory failure has developed. What kind of study would that be after seeing this negativity regarding surfactant? Do you think that we should invest in that type of trial because I imagine it would have to be a very large trial with thousands of patients that would potentially be exposed to this medication before the event happens? What do you think?

Willson: It would not be different in preemies because we have pretty good evidence of the rate of development of respiratory distress syndrome. 
You could take a group of 28-32-week preemies and have a good estimation of what the expected rate is. I don't think that would be particularly difficult. I do think that, in that particular patient population, there are very good data $^{7}$ that suggest that prophylaxis is better than rescue treatment. That's because once the lung is injured, the distribution of surfactant become more heterogeneous; it's not as effective. We have many older kids who are on increasing amounts of $\mathrm{O}_{2}$ and who get more and more hypoxic and end up intubated. I can't help but think that if we had a way to deliver surfactant before they required positive-pressure ventilation you might be able to show an effect. Yes, it would be an expensive and difficult study to do.

Restrepo: What about adults?

Willson: I don't care about adults. Actually, I do care about adults because our study 8 from 2 years ago included adults and kids with instillation. And you may know, it was totally negative. There was no impact on any outcome. But suffice it to say that, yes, it would be a difficult clinical study and a very expensive study. But in the preemie age group, it would not be an insurmountable problem because we do know what the incidence is in premature babies. I suspect that would be the group to start with.

Berlinski: I want to address the issue of powder inhalers and drug delivery even in small children. I think that if we look at the current available devices and drugs - and this comment might steal my thunder a little bit from when I talk about new devices-there is a group at Virginia Commonwealth University that has developed a system where they use what's called excipient-growth enhancement. This system uses 2 sources: one is a submicronic powder, and the second is something like sodium chloride, which, when they get together, experience hygroscopic growth. The particles are able to bypass the nasopharynx, make it into the airways, and reach the optimal particle size of 2-3 $\mu \mathrm{m}$ for the deposition of the drugs. That study has a lot of fluid dynamic work and some in vitro data. I think it's NIHfunded research, and they're now trying to move forward into specific drugs and use this concept. But the concept was actually published for noninvasive ventilation with a modified cannula $^{9}$ and invasive ventilation, ${ }^{10}$ in both pediatric and adult models. I think it's safe to say that things might change if this technology moves forward because it seems to be very efficient. However, there are no animal or human data yet, but in the future, we might be able to use those powder inhalers.

* James B Fink PhD RRT FAARC, James B Fink LLC, San Mateo, California, and Division of Respiratory Therapy, Georgia State University, Atlanta, Georgia, representing Aerogen.

$\dagger$ Neil R MacIntyre MD FAARC, Division of Pulmonary and Critical Care Medicine, Duke University, Durham, North Carolina, representing InspiRx.

\section{REFERENCES}

1. Lewis JF, Tabor B, Ikegami M, Jobe AH, Joseph M, Absolom D. Lung function and surfactant distribution in saline-lavaged sheep given instilled vs nebulized surfactant. J Appl Physiol 1993;74(3):1256-1264.

2. Calverley PM, Anderson JA, Celli B, Ferguson GT, Jenkins C, Jones PW, et al. Salmeterol and fluticasone propionate and survival in chronic obstructive pulmonary disease. N Engl J Med 2007;356(8):775789

3. Finer NN, Merritt TA, Bernstein G, Job L, Mazela J, Segal R. An open label, pilot study of Aerosurf combined with nCPAP to prevent RDS in preterm neonates. J Aerosol Med Pulm Drug Deliv 2010; 23(5):303309.

4. Kanmaz HG, Erdeve O, Canpolat FE, Mutlu B, Dilmen U. Surfactant administration via thin catheter during spontaneous breathing: randomized controlled trial. Pediatrics 2013;131(2):e502-e509.

5. Abdel-Latif ME, Osborn DA. Pharyngeal instillation of surfactant before the first breath for prevention of morbidity and mortality in preterm infants at risk of respiratory distress syndrome. Cochrane Database Syst Rev 2011;16;(3):CD008311.

6. Dijk PH, Heikamp A, Bambang Oetomo S. Surfactant nebulization prevents the adverse effects of surfactant therapy on blood pressure and cerebral blood flow in rabbits with severe respiratory failure. Intensive Care Med 1997;23(10):1077-1081.

7. Stevens TP, Harrington EW, Blennow M, Soll RF. Early surfactant administration with brief ventilation vs. selective surfactant and continued mechanical ventilation for preterm infants with or at risk for respiratory distress syndrome. Cochrane Database Syst Rev 2007;(4):CD003063.

8. Willson DF, Truwit JD, Conaway MR, Traul CS, Egan EA. The Adult Calfactant in Acute Respiratory Distress Syndrome (CARDS) Trial. Chest, in press.

9. Golshahi L, Tian G, Azimi M, Son YJ, Walenga R, Longest PW, Hindle M. The use of condensational growth methods for efficient drug delivery to the lungs during noninvasive ventilation high flow therapy. Pharm Res 2013;30(11):2917-2930.

10. Longest PW, Tian G. Development of a new technique for the efficient delivery of aerosolized medications to infants on mechanical ventilation. Pharm Res 2015;32(1):321-336.

This article is approved for Continuing Respiratory Care Education credit. For information and to obtain your CRCE

(free to AARC members) visit www.rcjournal.com

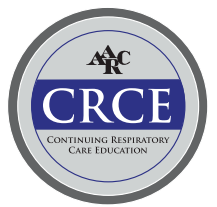

